\title{
طبيعة التقويم و أهمية الأطر السيكوبيداغوجية في تقويم الكفاعات
}

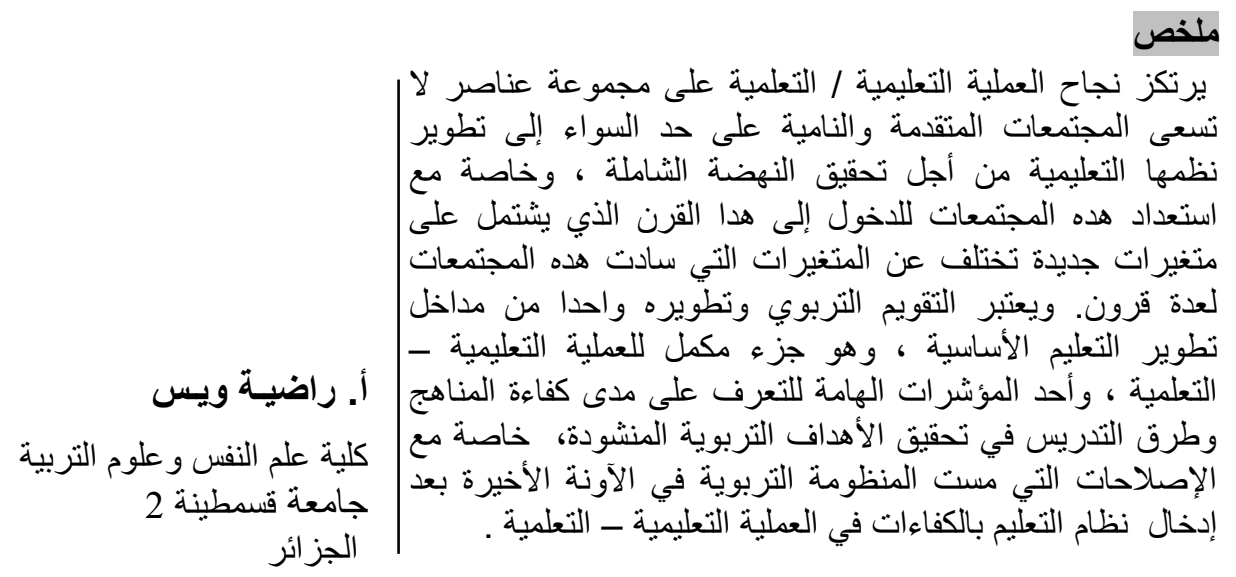

\begin{abstract}
مقدمة
Abstract

مـعد التقويم التربوي عنصر ا أساسيا في العملية

Developed societies and societies on track

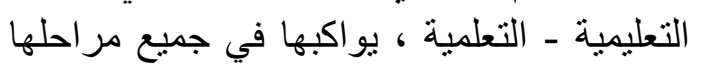

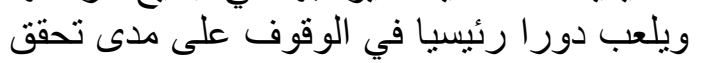
of development looking for the progress of their education system to achieve the overall development in particular, especially with the willingness of theses

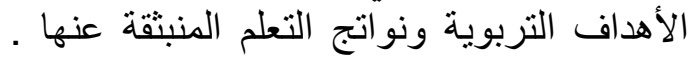
society to enter this century that include

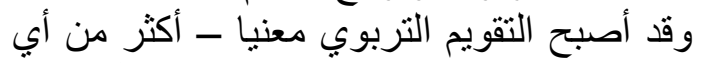

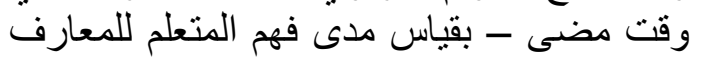

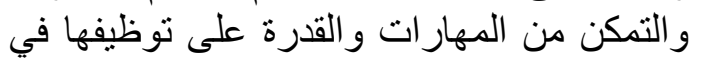

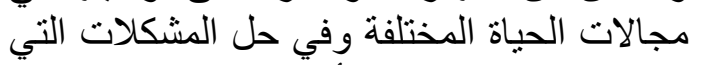

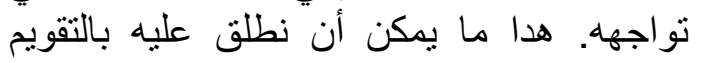

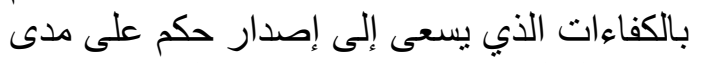

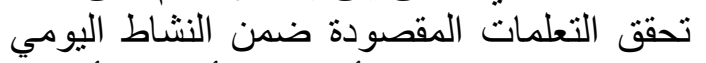

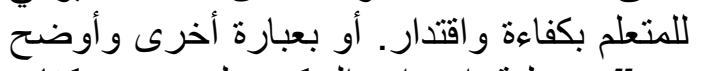

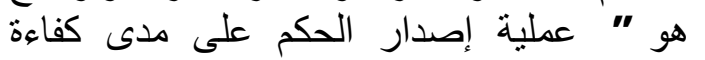
المتعلم التي هي بصدي التهد النمو والبناء من خلاءل أنشطة التعلم الّيتلفة." (حاجي فريد، 2005 new variants different off variables that prevailed in theses societies for centuries. Educational assessment and evolution are considered one of the main entrance to the development of education, it is an integral part of the learning-teaching process, and belongs to the important indicators to determine the extent of the effectiveness of teaching method and teaching in the achievement of the desired educational goals, especially with reforms that have affected the educational system recently after the introduction of the educational system by skills in the teaching learning process.
\end{abstract}


و عليه فإن تقويم الكفاءة هو أولا وقبل كل شيء تقويم القدرة على إنجاز نشاطات و أداء

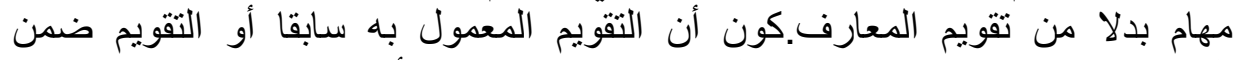

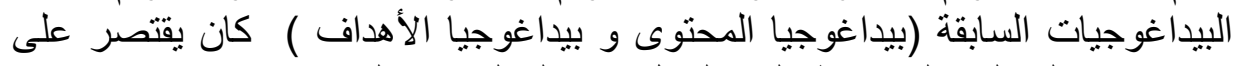

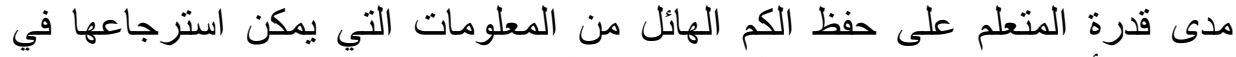

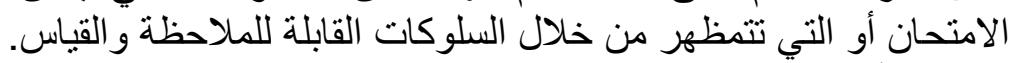

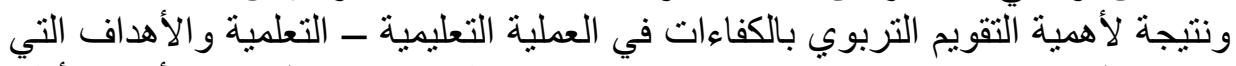

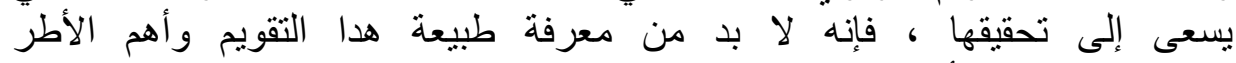
السيكوبيداغوجية و أهميتها في تقويم الكفاءات.

1- طبيعة التقويم التربوي بالكفاءات:

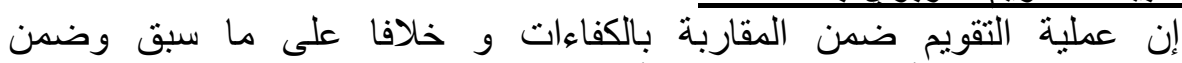
البيداغوجيات السابقة أصبح ينظر إلبها بأنها لبست معياء البهاء البها وحيدا لقياس ما هو منتظر

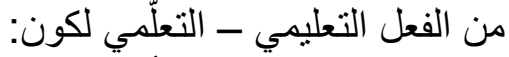

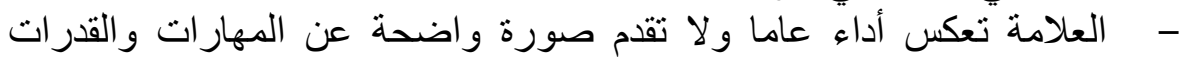

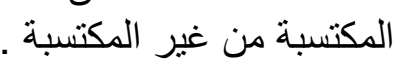

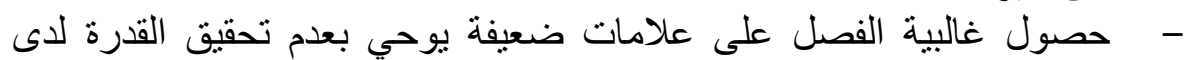
الكل، مما يجعل المدرس يعيد التعلم الذي يستجيب للغالبية المتعثرة مقابل تهميش الفئة القليلة التي حققت النجاح. - عصول غالبية القسم على معدل يوحي بتحقيق القدرة ، يجعل المدرس يتقدم في عله ويهمل المتعثرين.

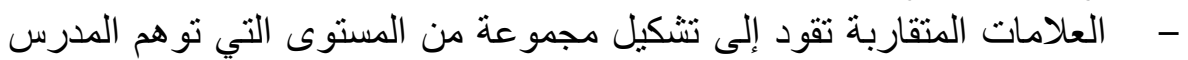

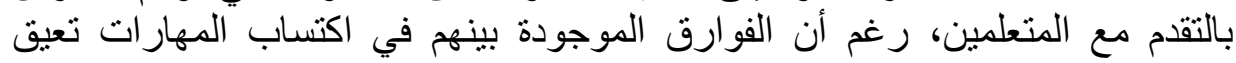
ونظر الهذه الاعتبار ات و غير ها وسعيا إلى تقدير موقع المتعلم على سلّم النمو تحقيق القدرة لاى الجميع.

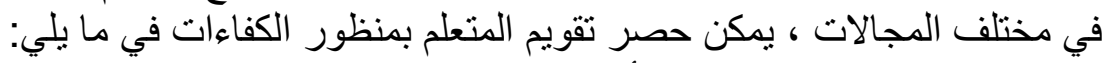
- - ت تنمية مستوى الكفاءة و الأداء لدياء.

- - تشخيص صعوبات التعلم و الكثف عن حاجهات المتعلم ومشكلاته وقدر اته قصد تكييف العمل التربوي. - - اختبار مدى نجاح الطر ائق و الأساليب المستعملة.

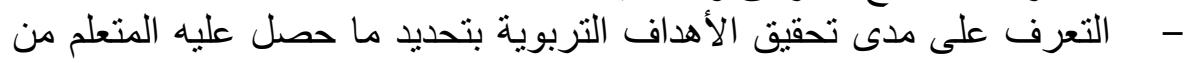
نتائج تعليمية. - الحصول على المعلومات اللازمة في تقويم المتعلم لتوجيهه حسب قدراته

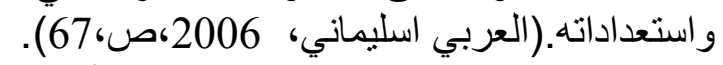

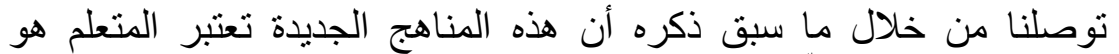

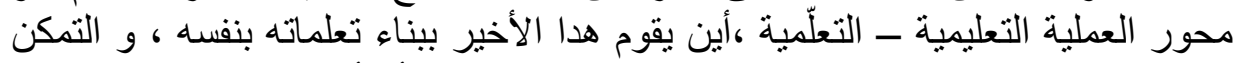
من اكتساب المعارف والكفاءات اللازمة ضمن وضئ وضعيات أو أنشطة تعليمية - تعلمية. 


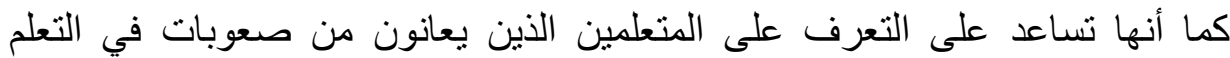

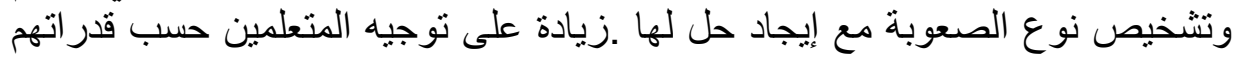

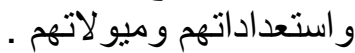

إضافة إلى ما سبق فإن عملية تقويم تعلّمات المتعلم ضمن هذه البيداغوجيا تركّز

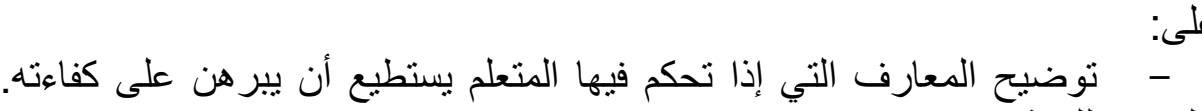
(الحسن اللحية، 2006، صناح، 35 35).

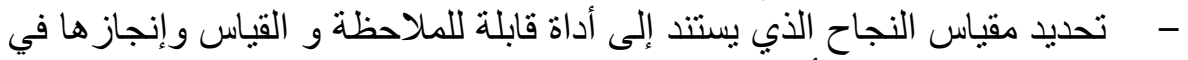
وضعيات التعلم، وهنا ينبغي أن نميز في عملية الثقويم بين الهدف ومؤشر الكفاءة، فإذاً

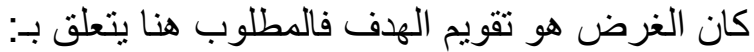

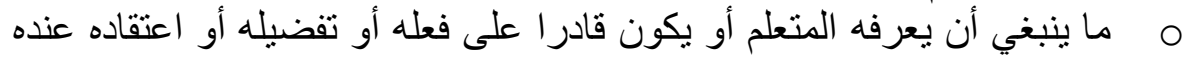

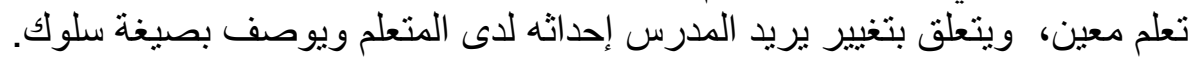
- -

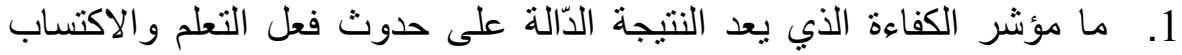

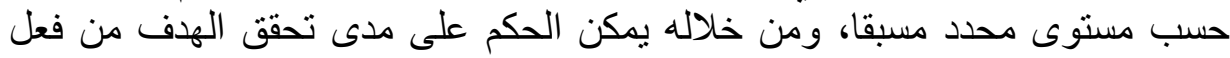

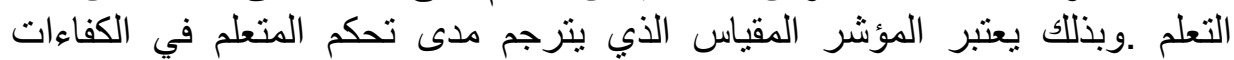
المكتسبة أو إبراز مقدر التغير في السلوك بعد تعلم ما. (الحسن اللحية، 2006، صن،

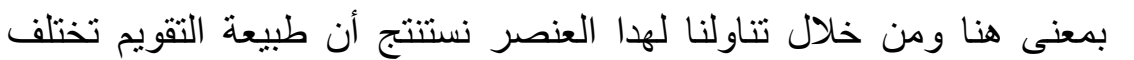

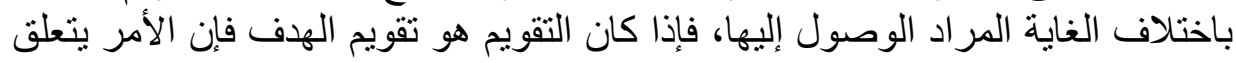

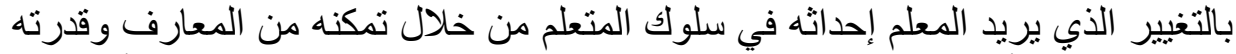

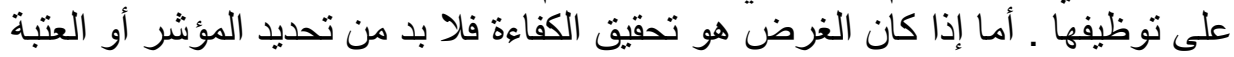

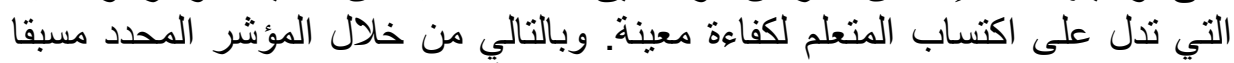

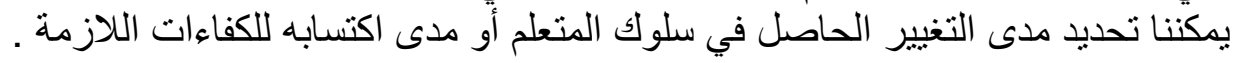

\section{2- الإطار السيكوبيداغوجي وأهميته في تقويم الكفاءات:}

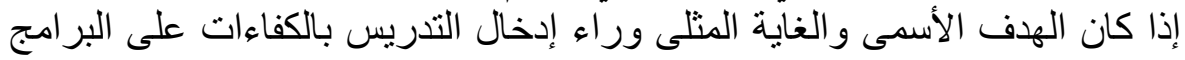

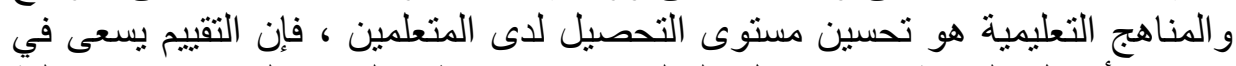

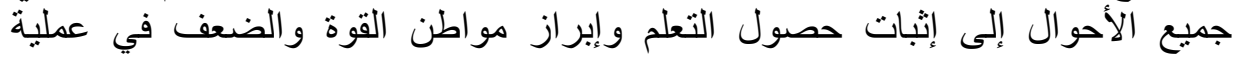

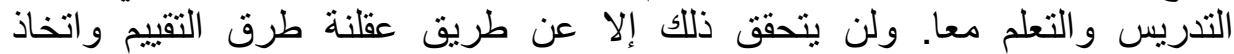

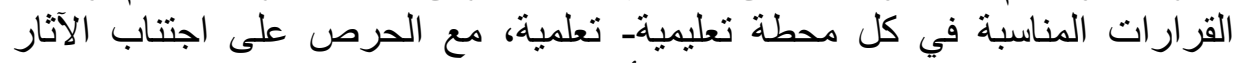

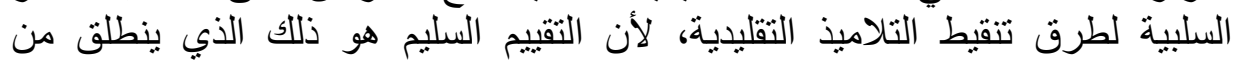

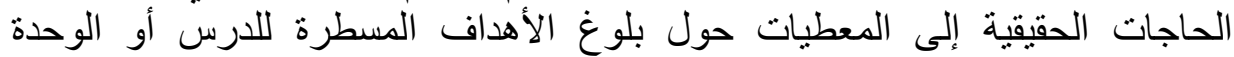

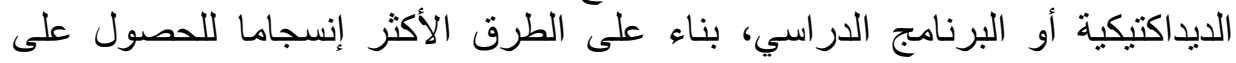

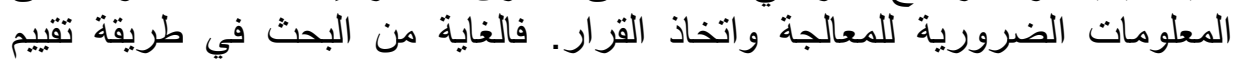
الكفاءات، لا تقتصر على إعطاء بدائل لممارسات سائدة في إطار مقاربات معينة في 
التدريس بقدر ما تسعى من وراء ذلك إلى فتح نافذة للتجديد مساءلة واقعنا من جهة

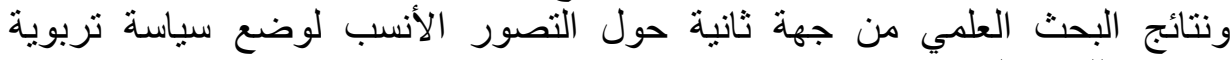

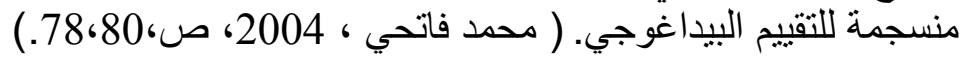

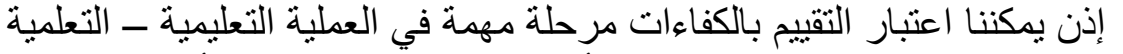

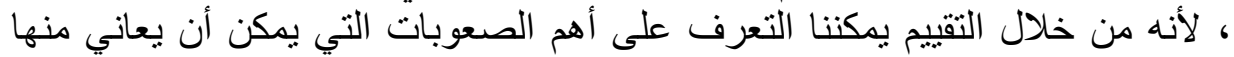

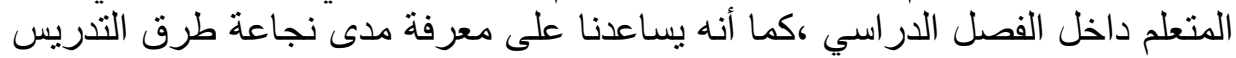

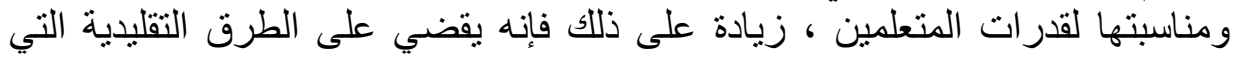

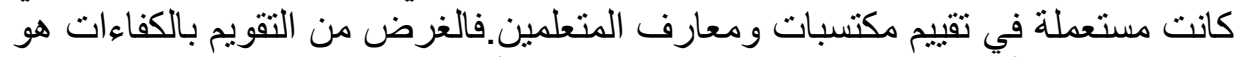

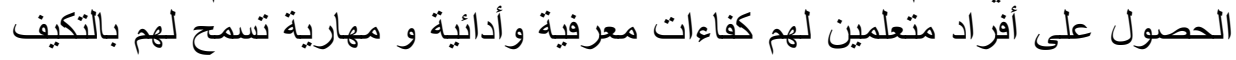

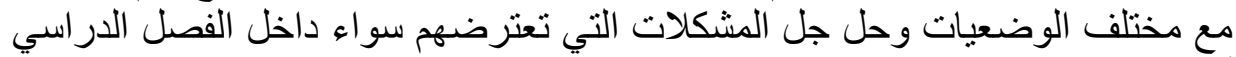
أو في الحياة العامة لهم .

\section{1-2}

لقد كان بلوم من بين الباحثين الأوائل الذين دعوا إلى عقلنة عملية التقييم التربوي،

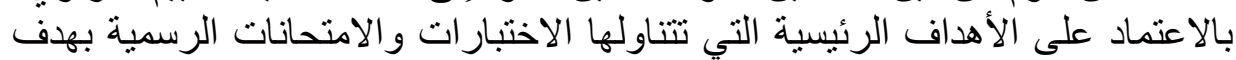

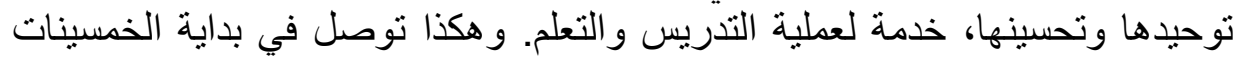

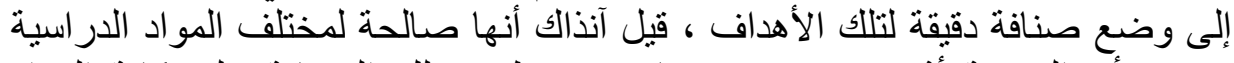

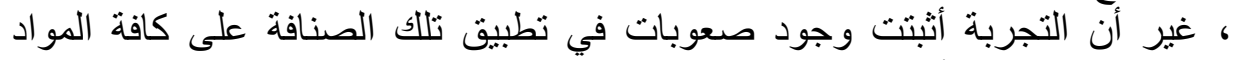

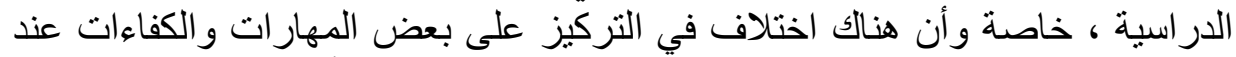

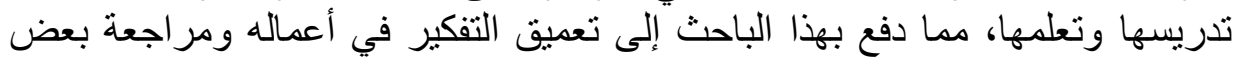

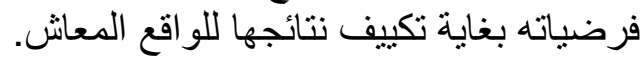

وبهذا قام بوضع الأسس المنهجية للتقييم التكويني و التقييم الإجمالي معتمدا في ذلكانك

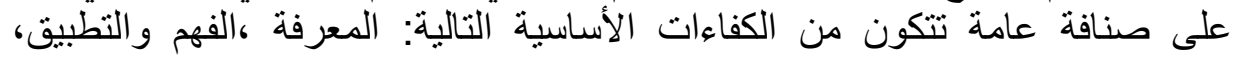

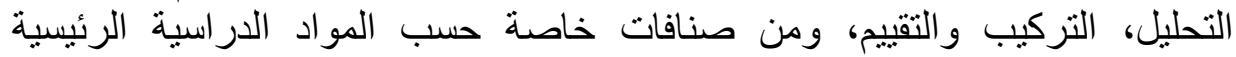

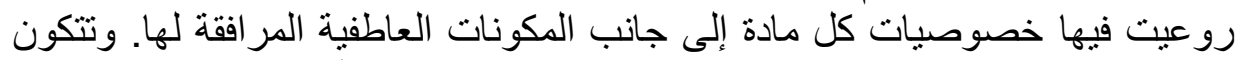

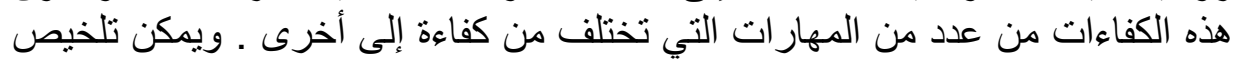

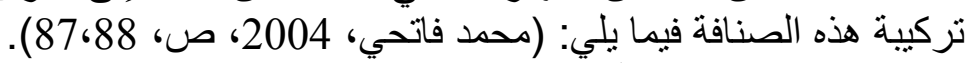

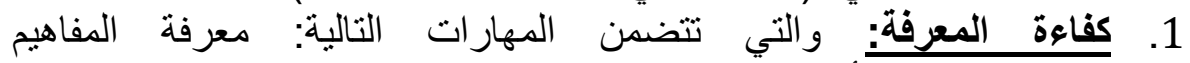

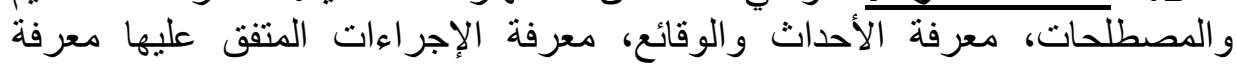

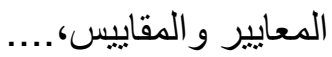

2. كفاءة الفهر: وتتكون من المهارات الرئيسية التالية: مهارة الشرح، مهارة التأويل ومهارة التعبير الخاصة ولكون.

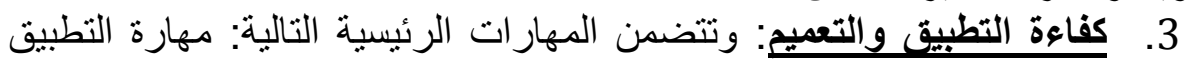
الوظيفي ومهارة التطبيق التعبيري. 
4. كفاءة التحليل: وتتضمن المهارات المركزية التالية: مهارة تحليل المكونات،

مهارة تحليل العلاقات، مهارة تحليل المبادئ و القو انين المهارئ المنظمة.

كفاءة التركيب: وتتكون من المهارات الرئيسية التالية: مهارة البحث عن العهائة العناصر

الأساسية، مهارة استخدام الفكر النقدي، مهارة التلخيص.

ومهارة التقييم الداخلي. التقيية: وتضمن المهار ات المركية الفرية التالية: مهارة التقييم الموضوعي

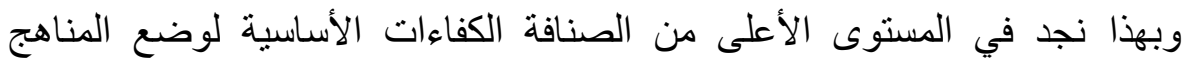

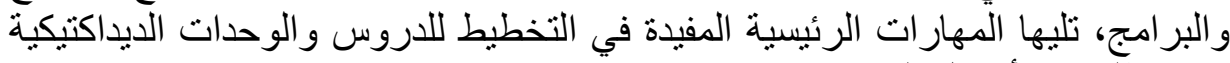

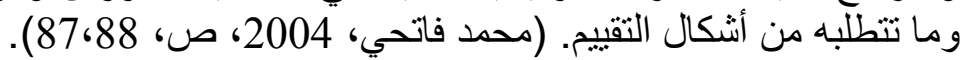

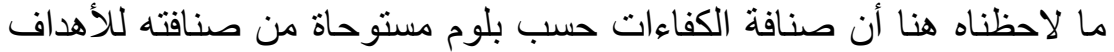

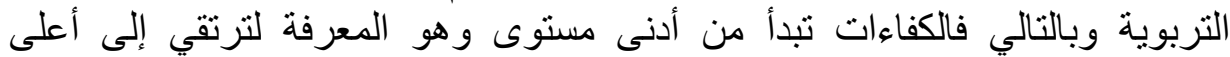

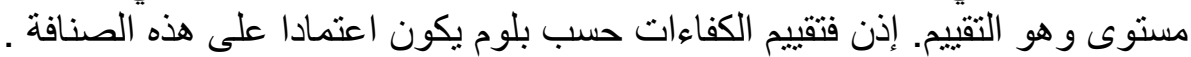

:Gagné 2-2

إذا كان بلوم يصنف موضوعات الهوات التعلم حسب مجالات ثلاثلة، هي المجال المعرفي

والمجال الحس حركي والمجال العاطفي، فإن غيره يفضل الحديث عن المعارف

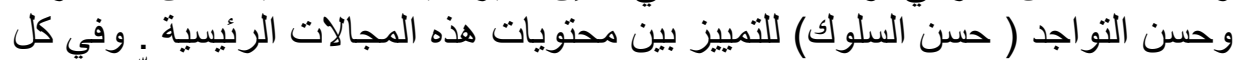

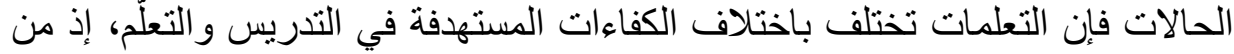

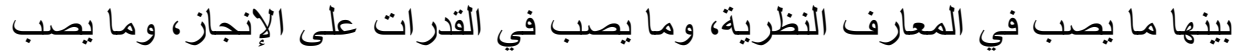

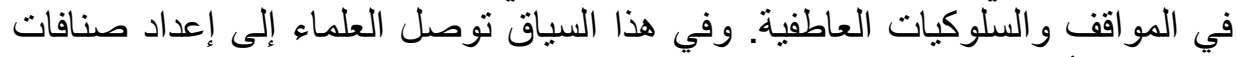

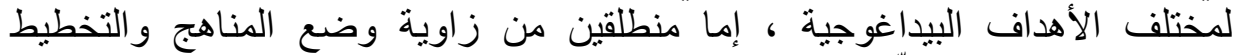

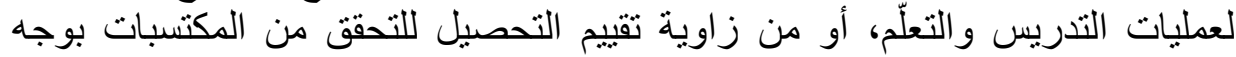

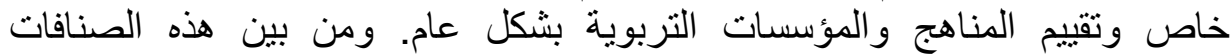

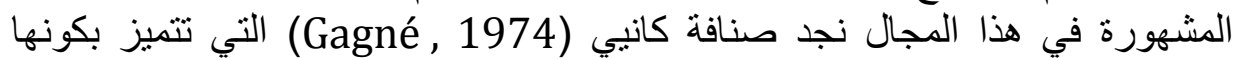
تتدرج في إطار نمط تدخل بيداغوجي معين يركز على الكفاءاء ات كمدخل لمختلف

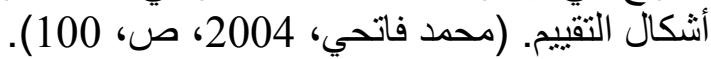

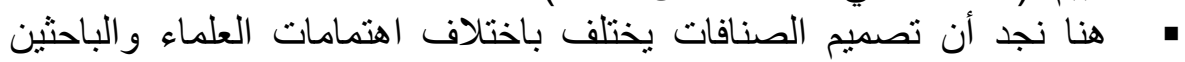

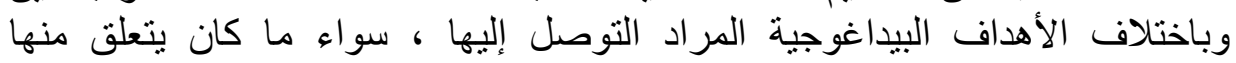

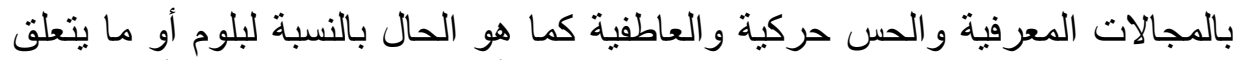

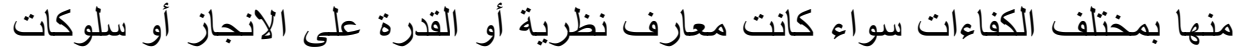

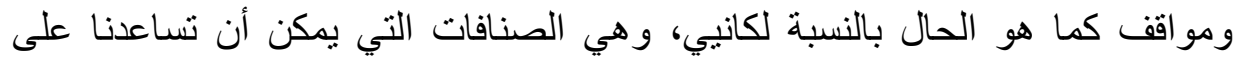

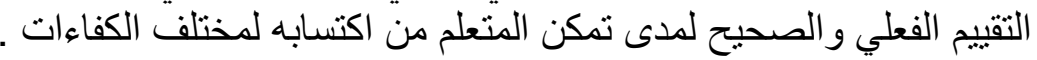

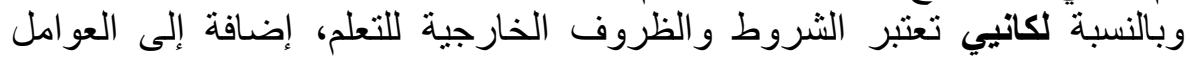
الداخلية المرتبطة بالمتعلم من أهم العوامل المؤثرة في التحصيل و المردودية المالية الدراسية.

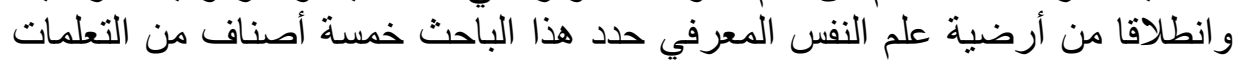


بإمكانها أن تضم مختلف الأهداف البيداغوجية التي تتضمنها المقررات والمناهج

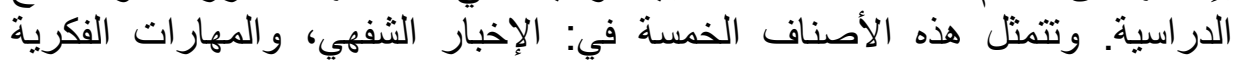

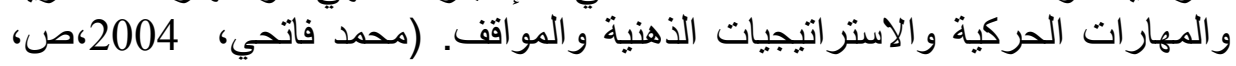

هده الفكرة تدفع بنا إلى القول أن التعلم بالنسبة لكانيي عبارة عن عملية تفاعل

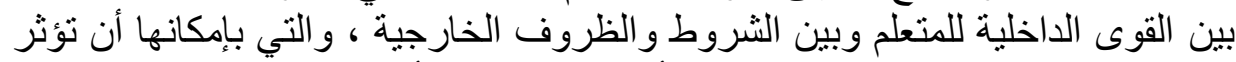

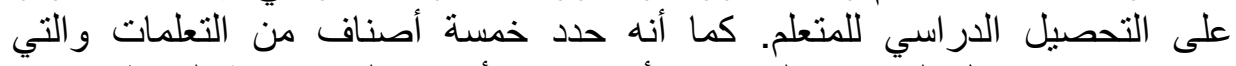

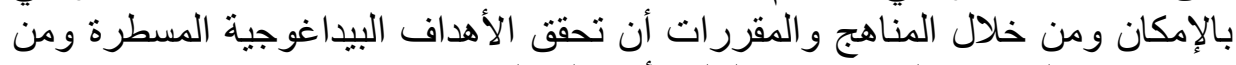

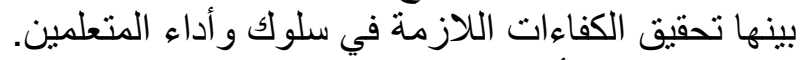

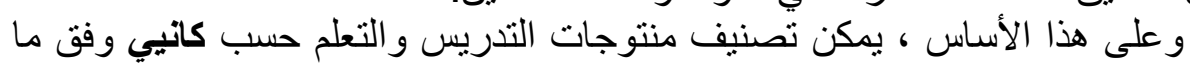

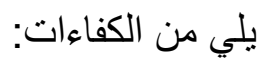

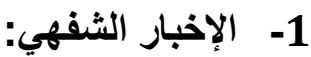

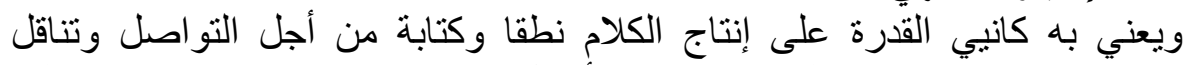

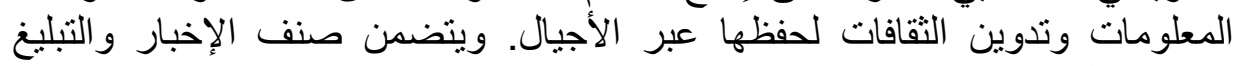

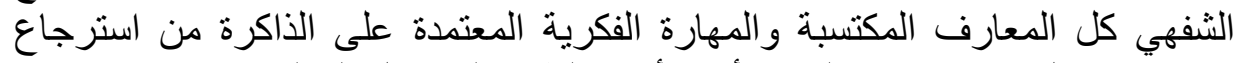

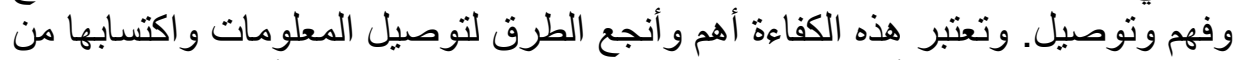

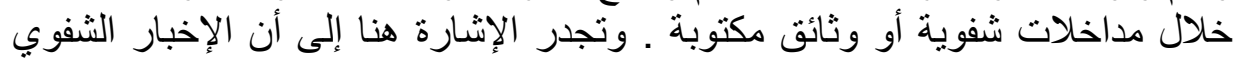

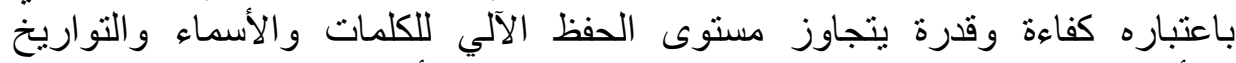

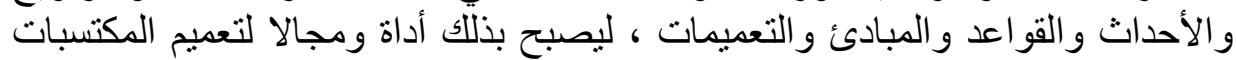

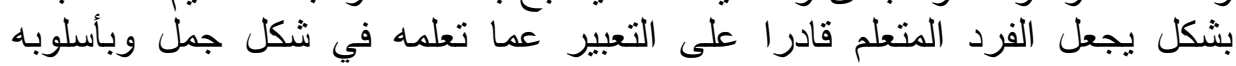
الخاص.

يمكننا اعتبار الإخبار الثفهي أداة ولغة تواصل بين المعلم والمتعلم وحتى بين

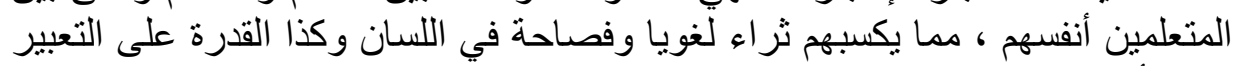

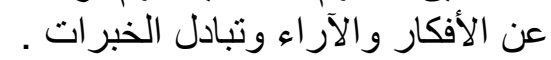

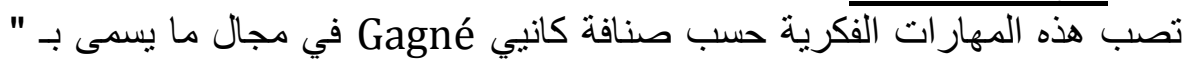

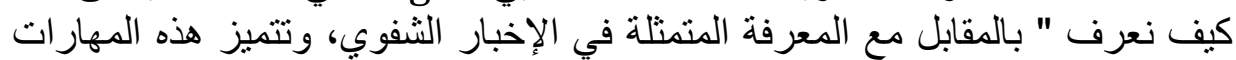

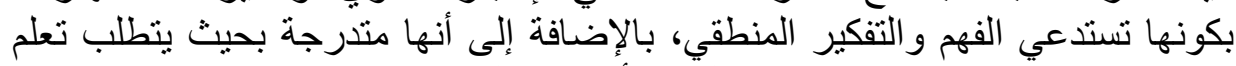

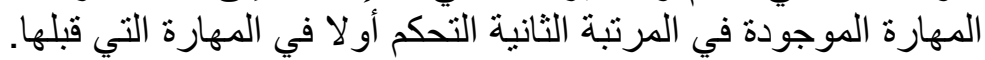

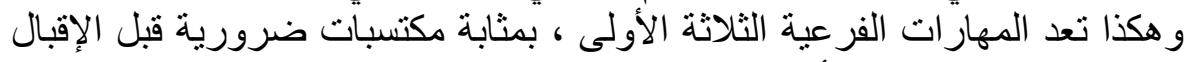

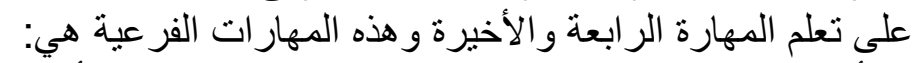

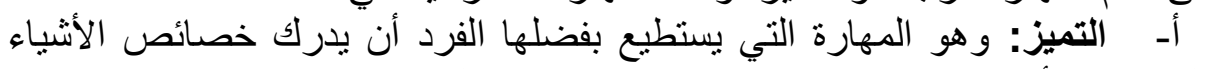

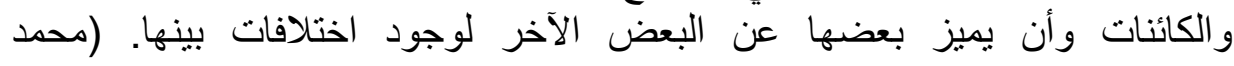

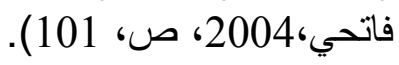


بمعنى هنا قدرة المتعلم على التمييز بين خصائص الأشياء ومميز اتها كالتمبيز

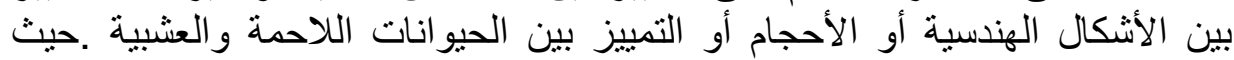
تعتبر هذه المهارة أولى المهار ات التي يجب الإ الثى المتعلم اكتسابها.

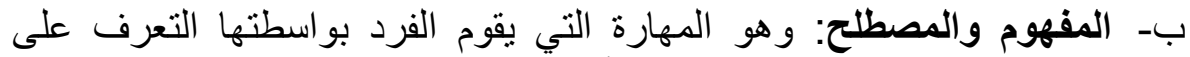

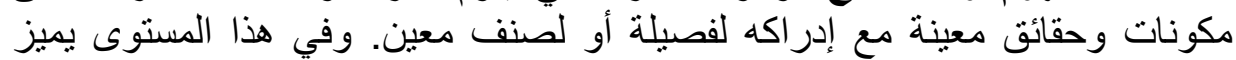

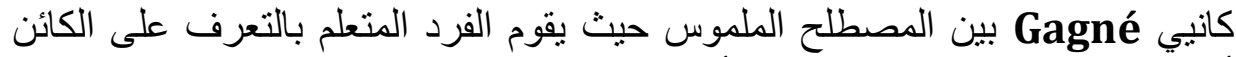
أو الثيء وترتيبه ضمن المجموعة أو الصنف الذي ينتمي إليه ، وبين المفهوم المعرف

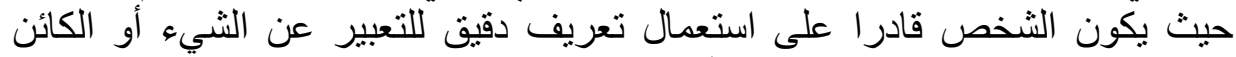

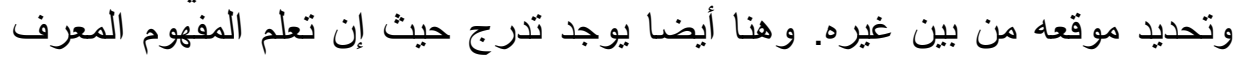

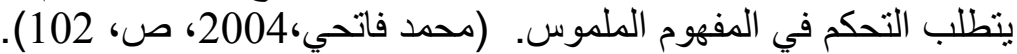

• المفهوم والمصطلح يعد المهارة الثانية التي يتوجب على المتعلم اكتسابها

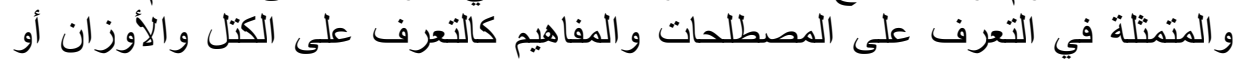

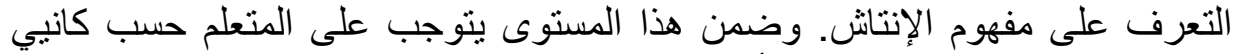
التمييز بين المصطلح الملموس أين تكون لدى الفرد المتعلم القدرة على التى التمييز بين

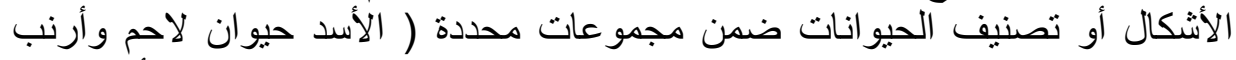

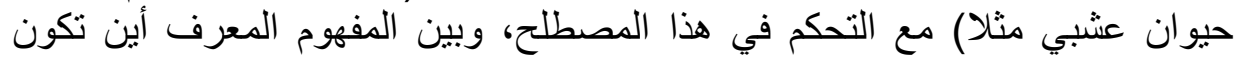
للمتعلم القدرة على التعبير على الأشياء باستعمال تعريف دقيق و و واضح ومد ومحدد.

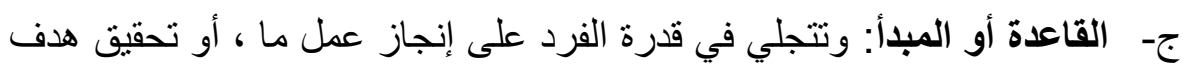

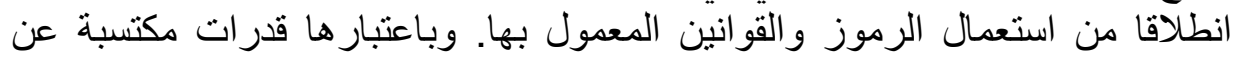

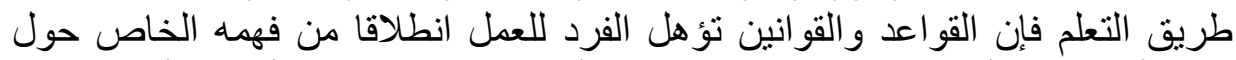

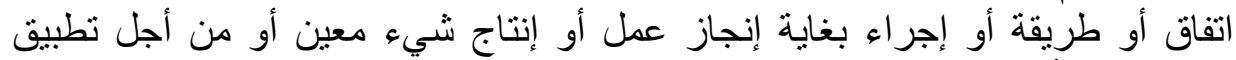

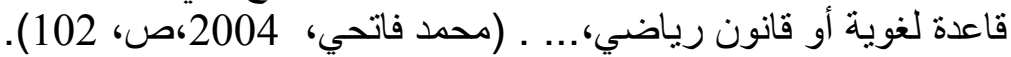

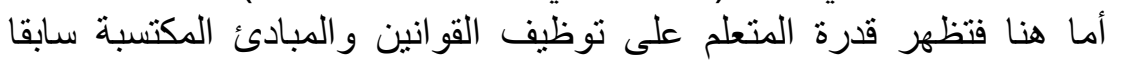

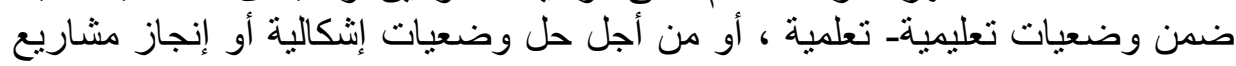

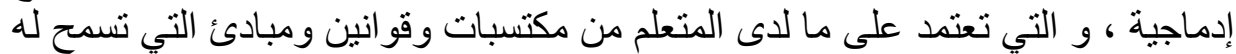

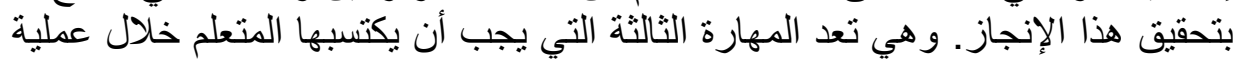

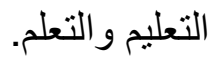

ح- القاعدة من المستوى الرفيع / الأعلى: وهي مجمو عة قو انين وقو اعد بسيطة

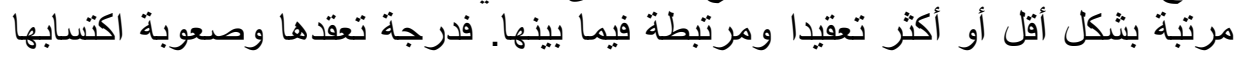

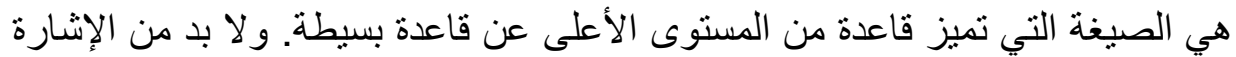

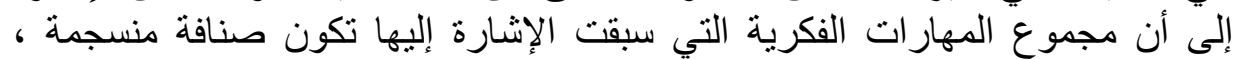

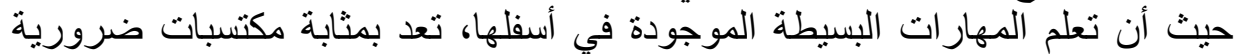
لتحقيق تعلم المهارات الموالية المعقدة. وهكذا تكون مهارة التمييز بين الأشياء أساسية 
وضرورية لاكتساب المفاهيم والمصطلحات التي تكون بدورها ضرورية لاكتساب الماب المياب القواعد التي توجد في المستوى الصنافي الموالي ـ (محمد فاتحي، 2004،صن، 102).

الملاحظ هنا أن النجاح في تطبيق قاعدة أو قانون من المستوى الرفيع يتطلب

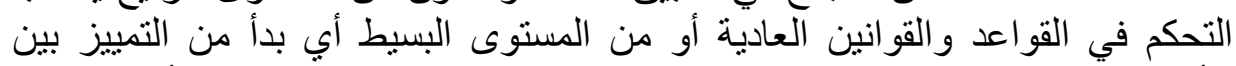

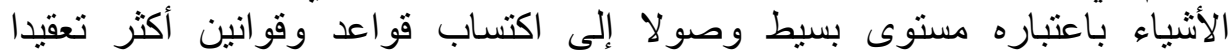
باعتبار ها مستوى رفيع أو أعلى. باءرى

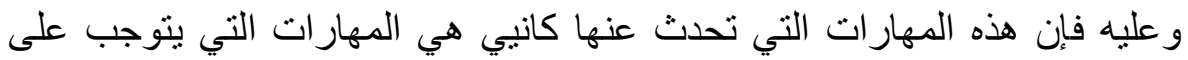

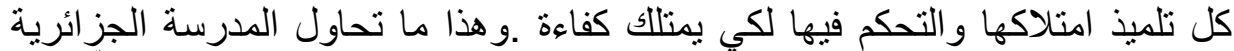
الوصول إليه من خلال مناهجها الدر اسية وما تتضمنه من وضعيات تعليمية ــ تعلّمية

\section{3- المهارات الحركية :}

هي تللك التي تسمح بالتحكم بشكل مرن و دقيق وات وملائم في إنجاز عمل يتطلب

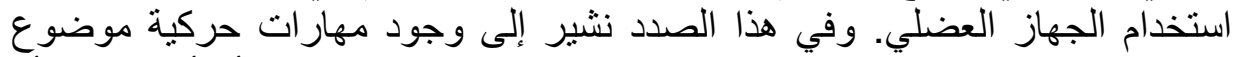
التدريس والتعلم، تتضمنها المقررات الدراسية، نذكر منها مسك القلم أو أداة الرسم أو أو

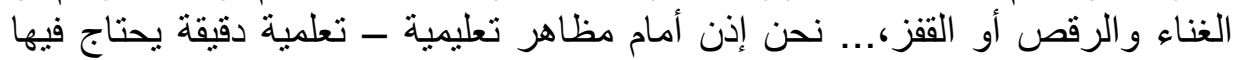
المتعلم إلى التحكم في عضلاته وتسخير ها لتحقيق أهداف تربوية معينة. كمانة كما أن تعلم

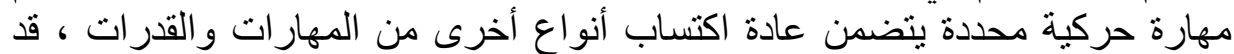

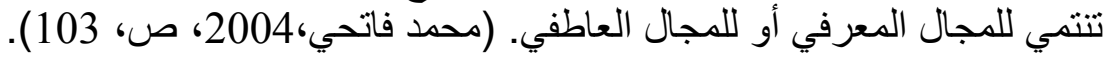

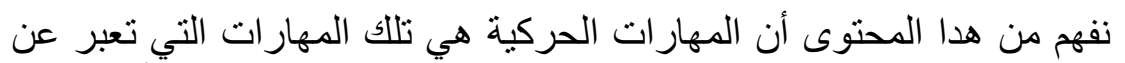
القدرات الحركية للمتعلم والتي تتدرج من التهن البسيط إلى المعقد كتعليم المتعلم أو لا كيفية

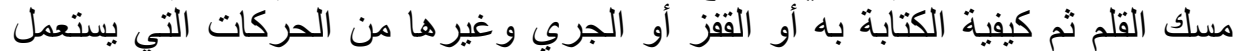

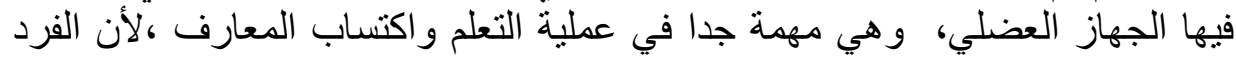

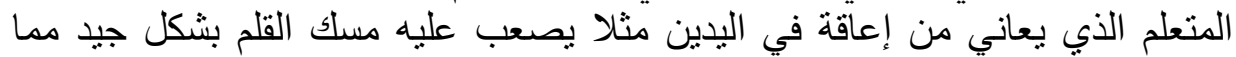
يؤثر على نتائجه الدر اسية .

\section{4- الاستر اتيجيات المعرفية:}

تشكل هذه الاستراتيجيات المعرفية قدرات فكرية منتظمة، تمكن المتعلم من التأثنير

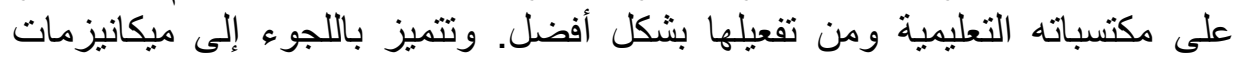

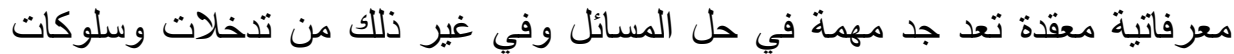

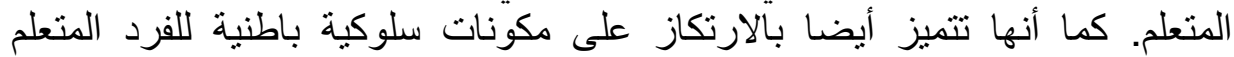

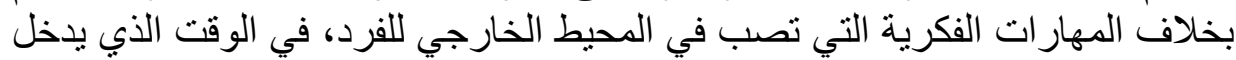

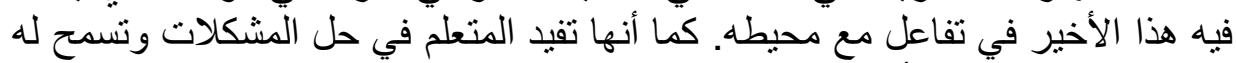

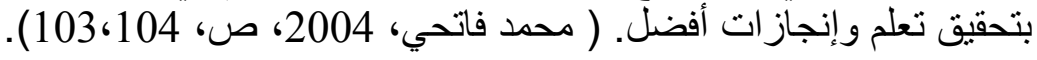

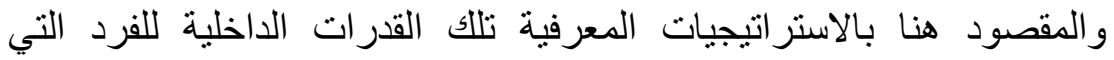

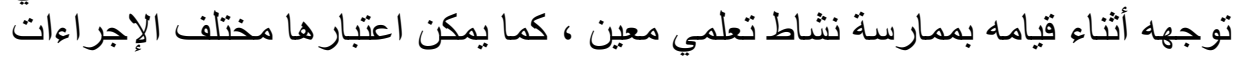




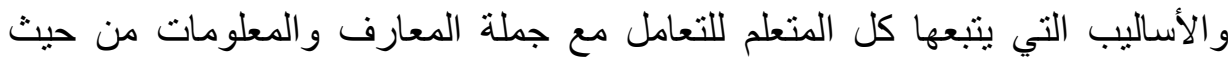

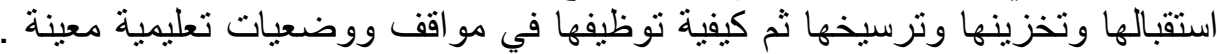

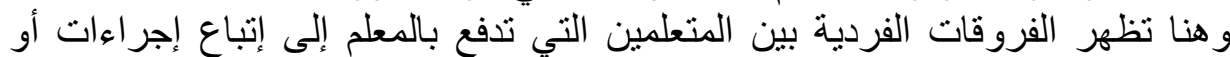
استر اتيجيات للتعامل مع هذه الفروقات.

و على هذا الأساس يعتبر كانيب الاستر اتيجيات الذهنية أو المعرفية عنصر أسنا أساسيا

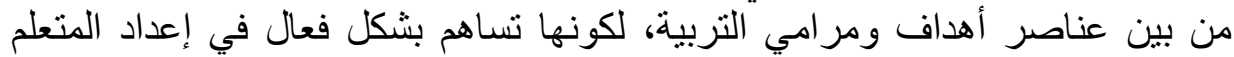

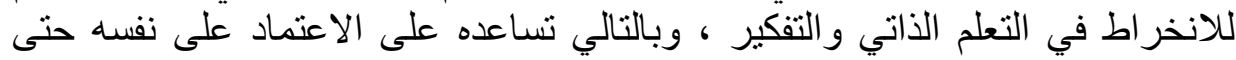

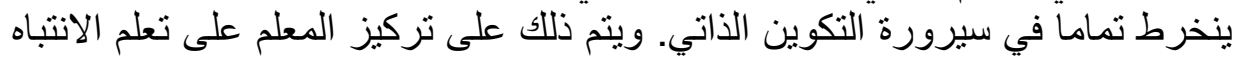

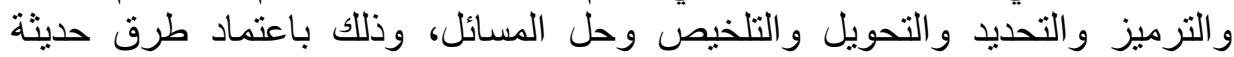

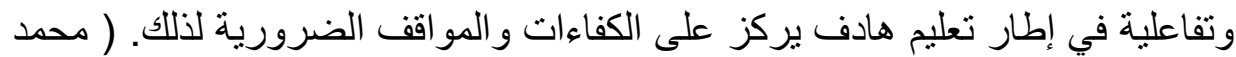
فاتحي، 2004،صن، فئن 104،103).

• إذن هذه الاستر اتيجيات تسمح للمتعلم بالاعتماد على نفسه من حيث التفكير و بناء

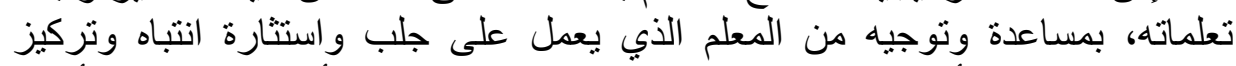

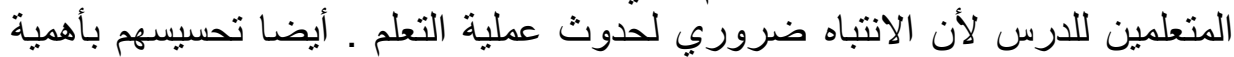

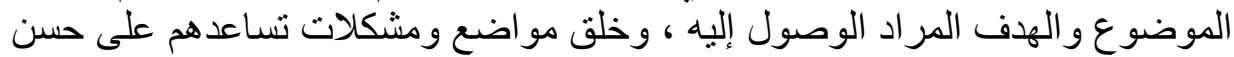

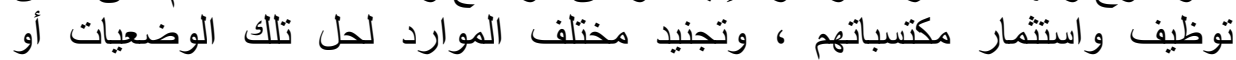

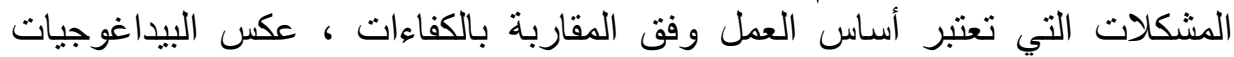

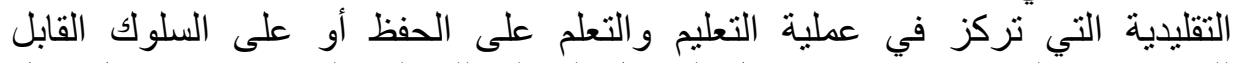

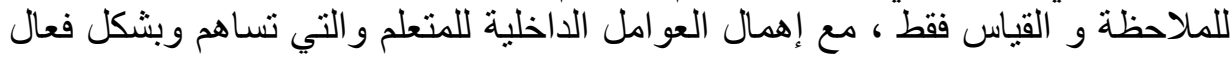
في عملية التعلم

\section{5- المواقف والاتجاهات:}

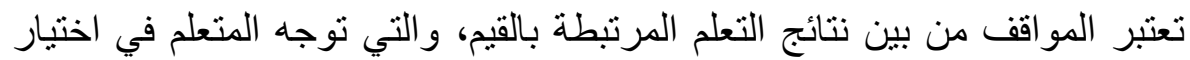

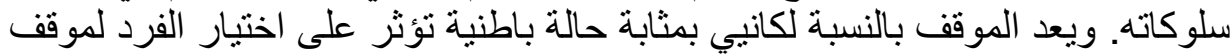

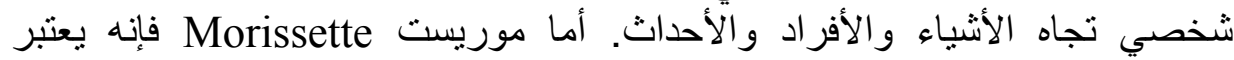

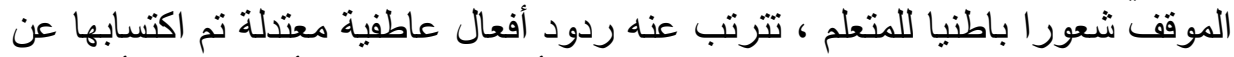

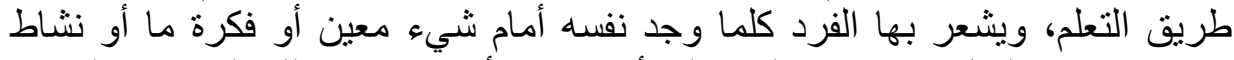

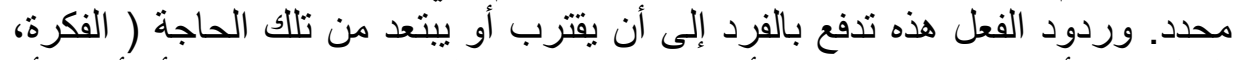

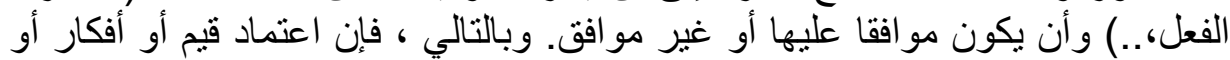

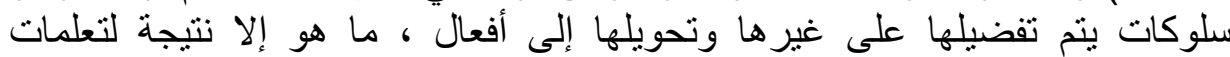

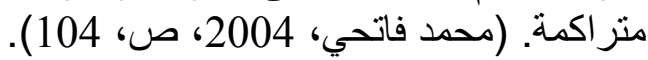

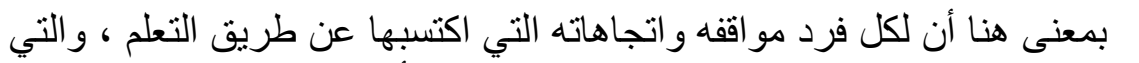

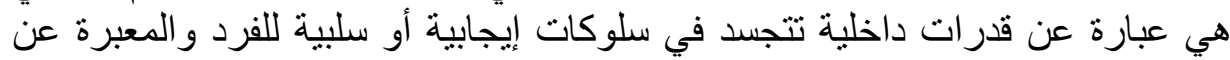


خلفيته الثقافية والاجتماعية و الأخلاقية وغير ها من القيم والعادات. كما ينتج عن هذه

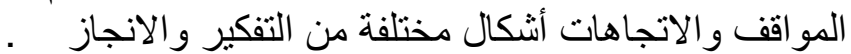

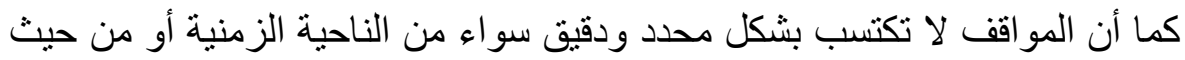

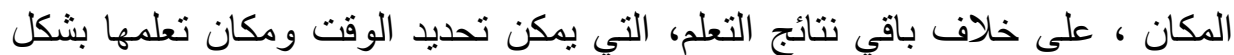
أفضل، حيث أن اكتساب المواقف بتطلب التبل وضع المتعلم في سياقات تربوية يقوم فيها بأعمال و أنشطة معينة، تجعله أمام قيم محددة تدريجيا أو يرفض فئها حسب في طبيعة مشاعره

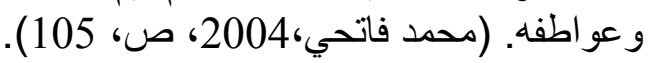

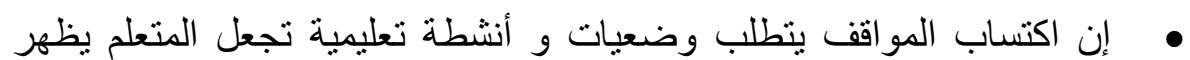

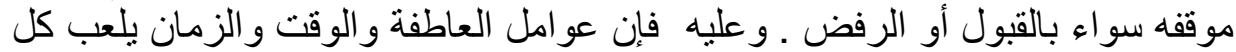
منها أدوار أساسية في اكتساب المو اقف والفئ والسعي إلى التحكم فيها.

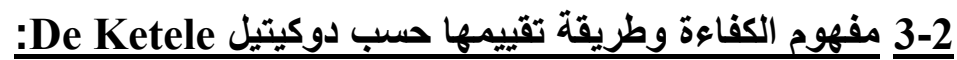

من أنسب التعاريف التي أعطيت للكفاءة بهدف تقبيمها التعريف الذي قدمه فريق الباحث البلجيكي دوكيتيل (1989, De Ketele ) و الذي يقول فيه إن :" الكفاءة هي الإني هدف إجرائي في وضعية معينة من الإنجاز" ـ و والهدف الإجرائي حسب " دوكيتيل

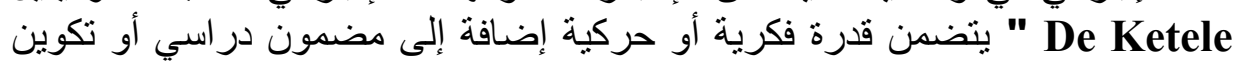

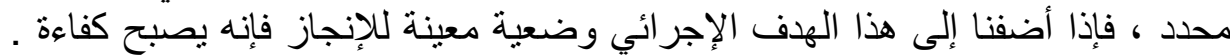

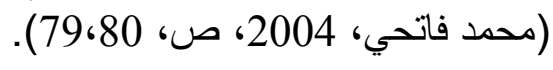

بمعنى هنا أن الهدف الإجرائي هو الذي يحدد نوعية السلوكات التي سيكتسبها

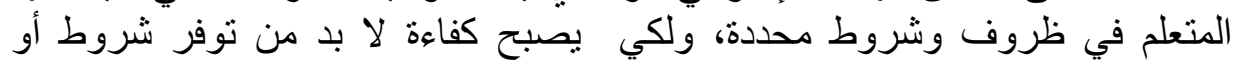

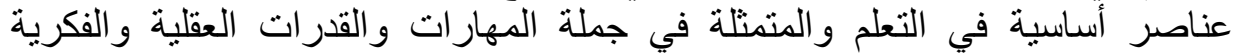

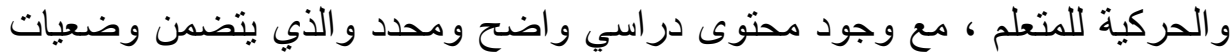

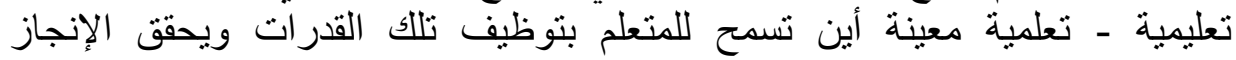

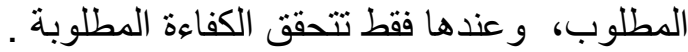

وفي نفس السياق يميز دوكيتيل De Ketele بين الكفاءة الأساسية والكفاءة

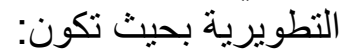

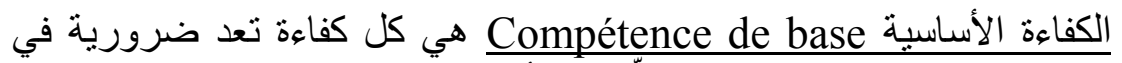
مرحلة معينة من إنجاز المقرر لمتابعة التعلّمات الأساسية المقبلة.

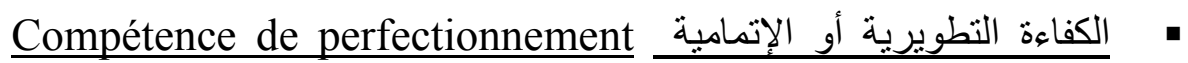
هي كل كفاءة غير ضرورية ، إلا أنها تعد جد مفيدة لمتابعة التعلمات الأساسية المقبلة

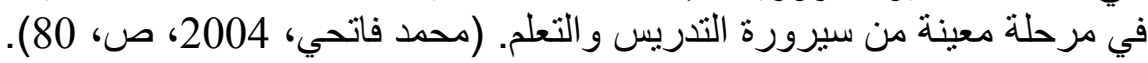

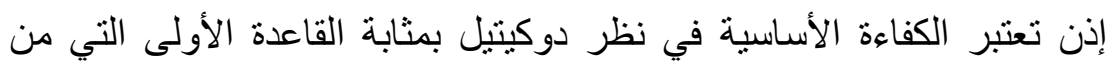

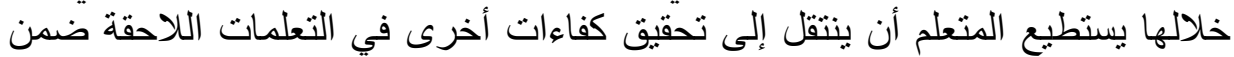


وضعيات و أنشطة تعليميةـ تعلّمية ، و التي تنجز من خلال قدرات ذهنية وحركية تجسد

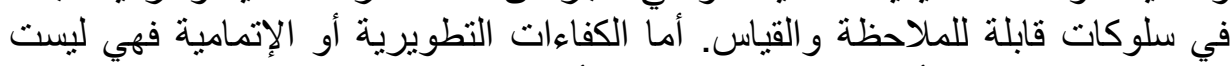
ضرورية لكنها مهمة أيضا في تحقيق تعلمات أخرى ضمن سيرورة تعليمية - تعلمية. هذا يعني أن الكفاءات الأساسية عبارة عن أهداف أكثر تعقدا من الأهداف الإجر ائية

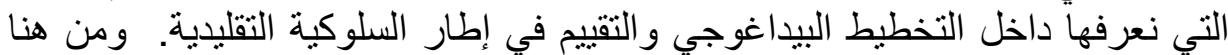

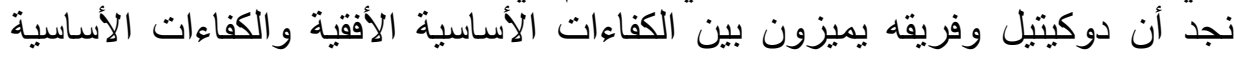
الخاصة بالمو اد الدر اسية على النحو التالي :

الكفاءات الأساسية الأفقية Compétences de Base Transversales وهي

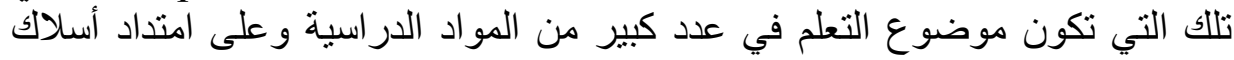

تعليمية مختلفة.

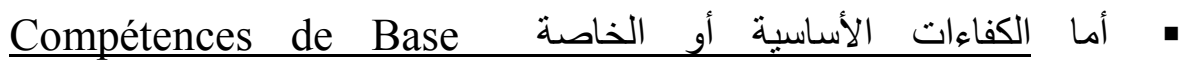
فإنها ترتبط بالمو اد الدراسية ومو اد التكوين التي ينحصر تعلمها في سياق تعليمي وفي مادة در اسية معينة.

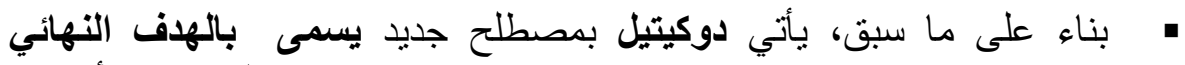

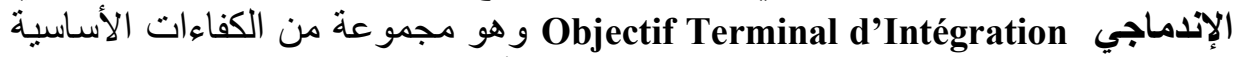

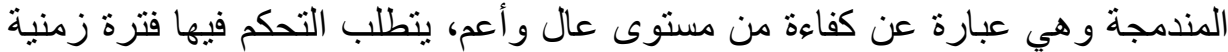

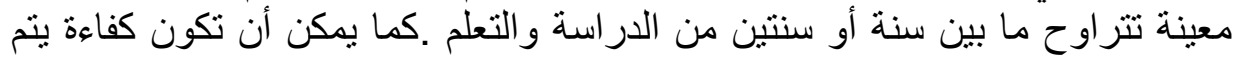
تشغيلها في وضعية إدماجية ذات دلالة بالنسبة للمتعلم. أما فيما يخص تقييم الكفاءات فقد صنف دوكتيل التقييم التربوي إلى أربعة أنواع رئيسية وهي التقييم التوجيهي Evaluation d'Orientation والتقييم من أجل

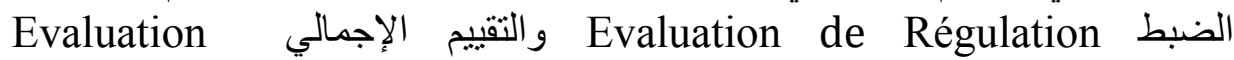
Evaluation de Certificative et de وتقييم الإشهاد و الضبط Certification Régulation

1. يقع التقييم التوجيهى Evaluation d'Orientation في بداية السنة أو

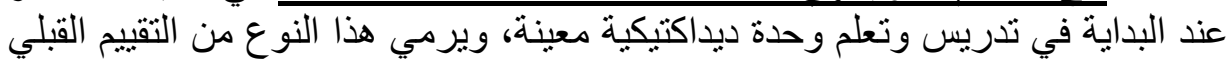

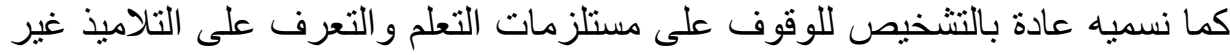

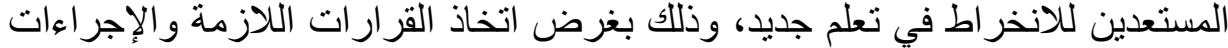

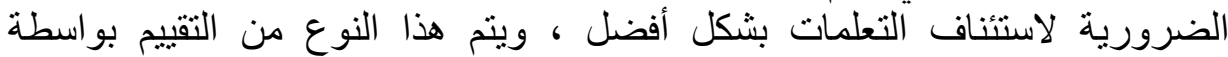

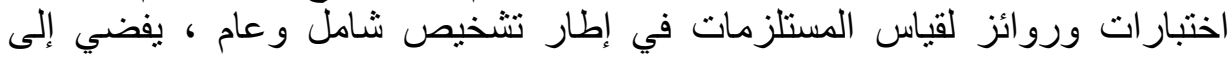
تزويد التلاميذ الذين لا يتحكمون في الكفاءات الأساسية بالدعم والتقوية المناسبة لكل

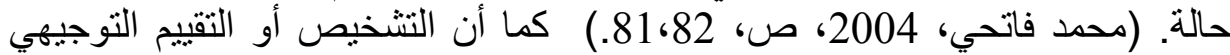
يهم الأهداف النهائية الادماجية أوالكفاءات الأساسية لنهاية السنة السابقة أو للوحدة التهائ

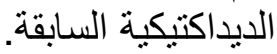




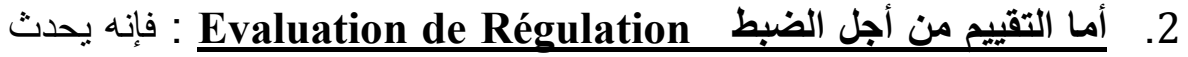

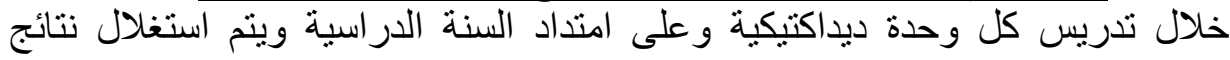

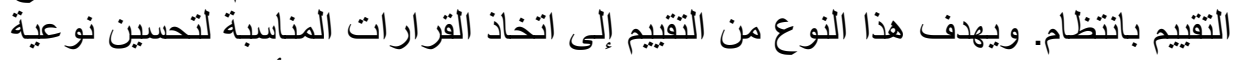

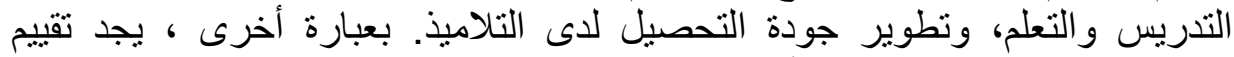

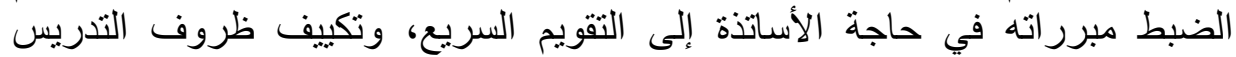

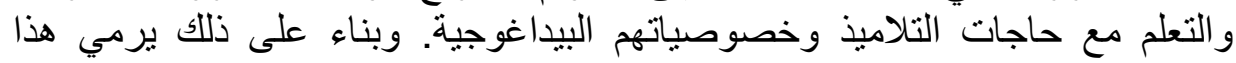

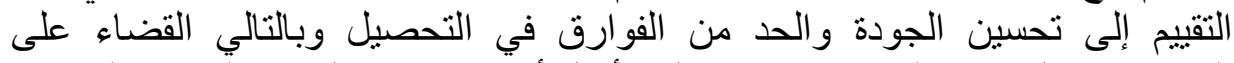
الصعوبات قبل استفحالها ـ كما يرمي إلى تأهيل أكبر عدد من التنلاميذ لمنابعة التدريس

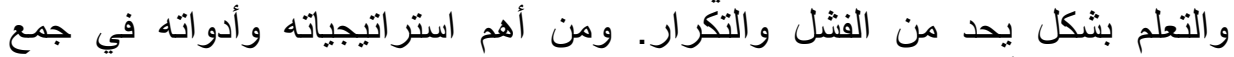

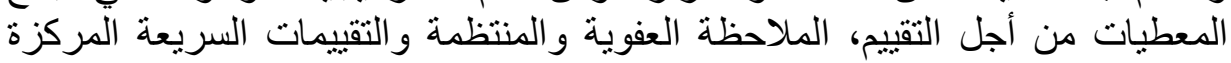
وتحليل أخطاء التلاميذ الخاصة والمتكررة في إطار مقاربة التشخيص - التصحيح وتقديم الدعم و التقوية .

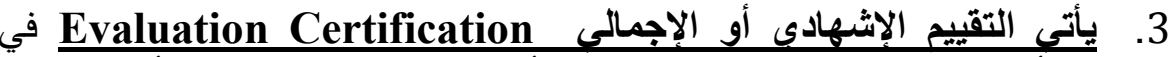

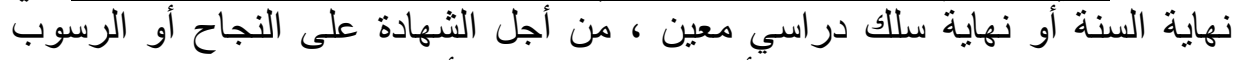

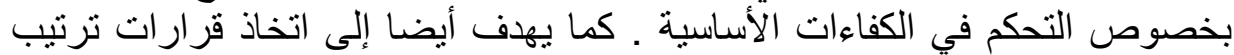

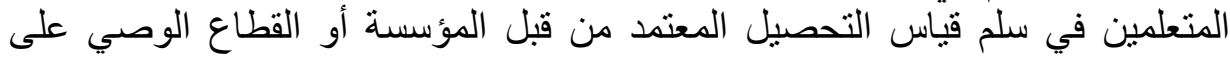

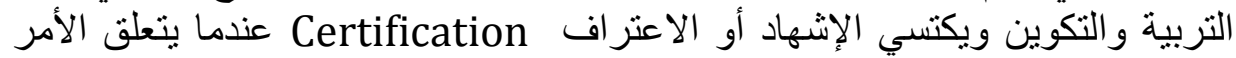

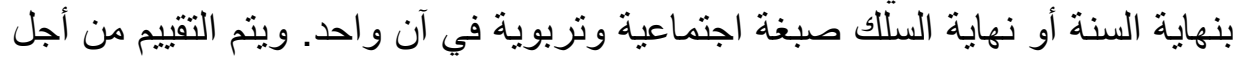

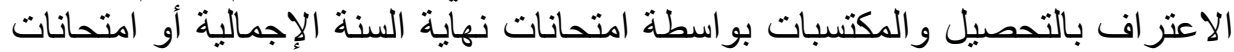

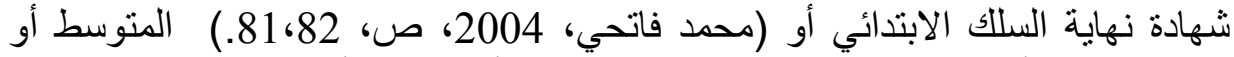

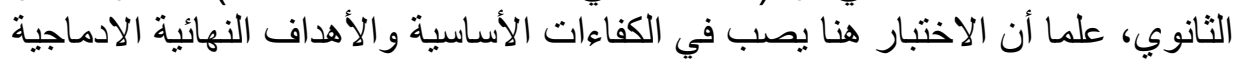

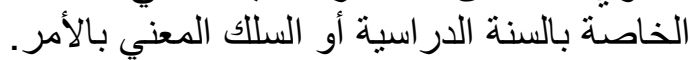

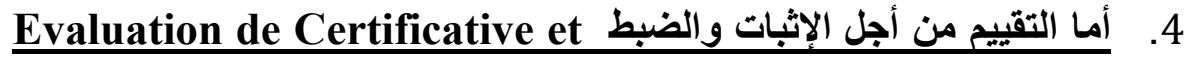

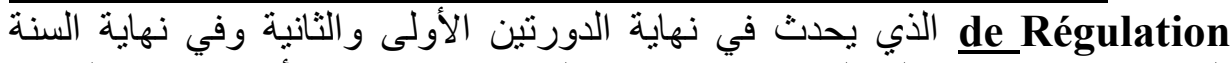

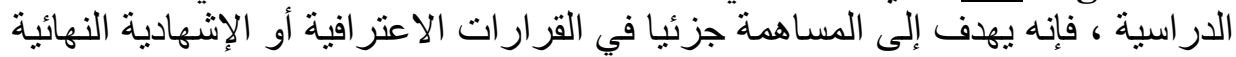

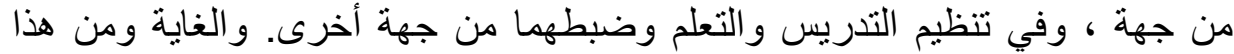

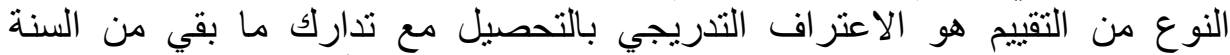

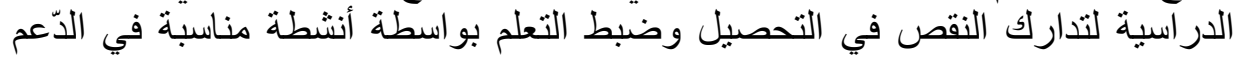
والتقوية، مما يجنب المتعلمين الرسوب التبل المبكر وغير المبرر تربويا. (محمد فاتحي،

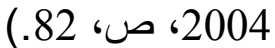

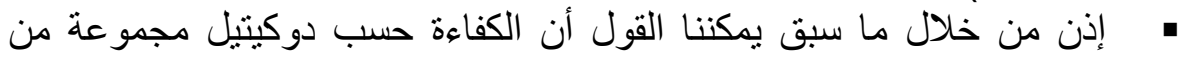

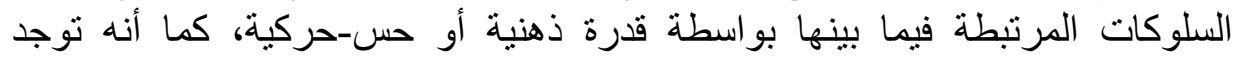

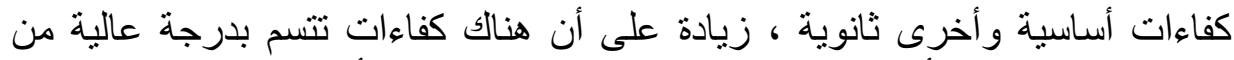
التعقيد وكفاءات دنيا أقل تعقيدا من حيث الاكتساب و التحكم. أيضا قسم دوكيتيل التقييم 
التربوي إلى أنواع كل نوع له مرحلة معينة ينفذ فيها وله هدف خاص يسعى إلى تحقبقه .

\section{4-2 تقسيمات كاردينى Cardinet للكفاءات الأساسية وطريقة تقيمها:}

إن التقييم حسب كارديني يسعى إلى خدمة المتعلم و أسرته و أستاذه، كما أنه يساهم إنهاء

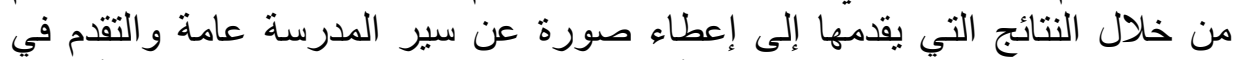

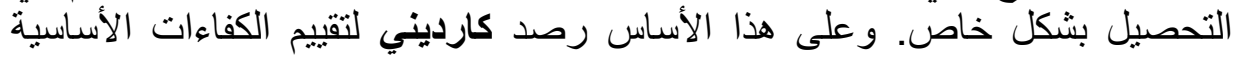

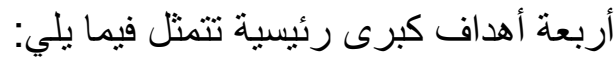

1. تحديد القرارات البيداغوجية بخصوص التعلم لدى كل تلميذ وتلميذة ، بغاية

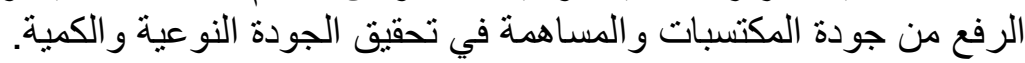

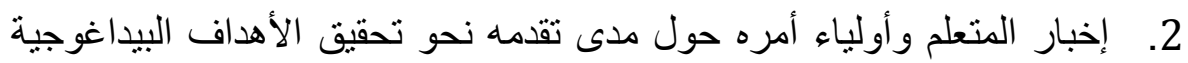

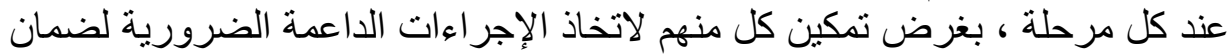

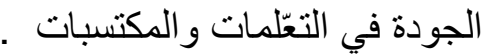

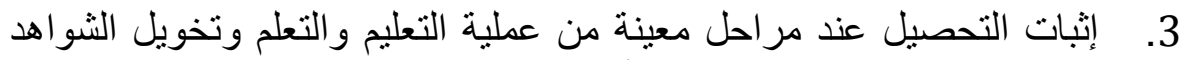

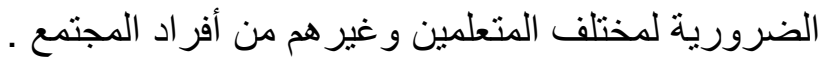

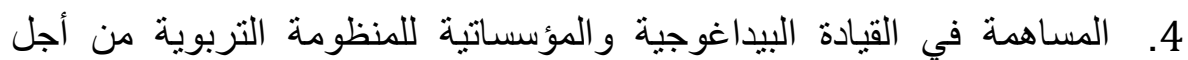

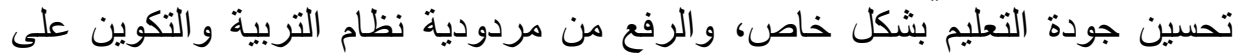

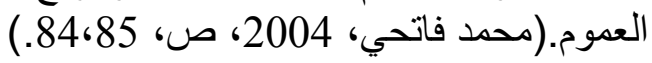

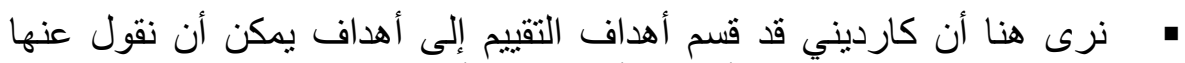

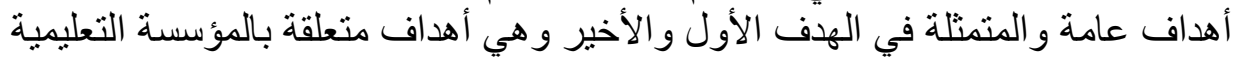

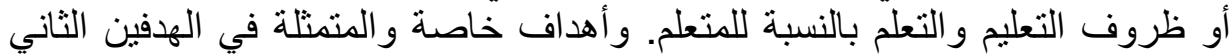

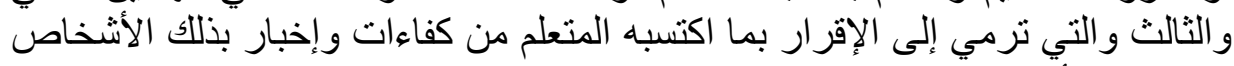
المعنيين (الأولياء).

و على هذا الأساس يصنف كارديني التقييم التربوي إلى نوعين التقييم Evaluation و التكويني Evaluation Formative Sommative

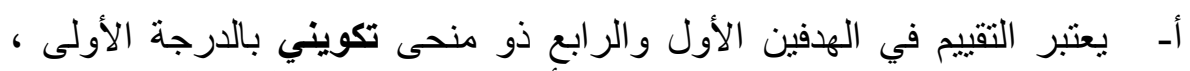

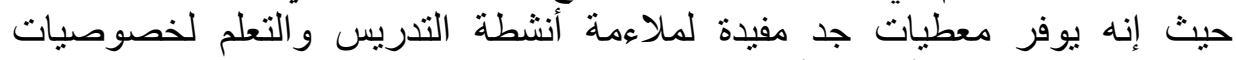

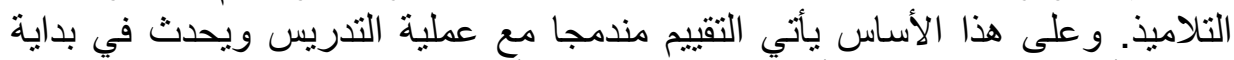

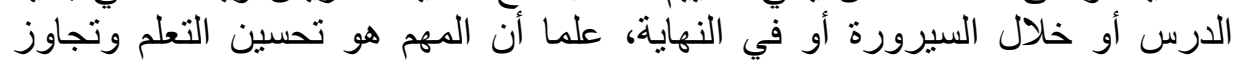
التعثر ات و النقص في التحصيل. التول

ويمكن للتقييم هنا أن يقارن بين نتائج المتعلمين في الكفاءات الأساسية وبين مؤشرات التحصيل المحددة في بلوغ كل هدف بئن بيداغوجي، كما بمكنه القيام بتحليل 
أعمال فرعية مرتبطة بالكفاءات الأساسية أكانت أهدافا مرحلية أو مستلزمات لمرحلة

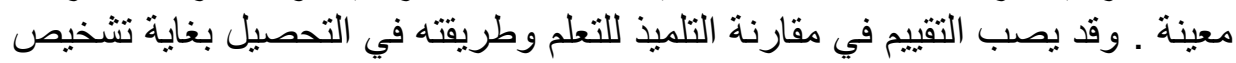

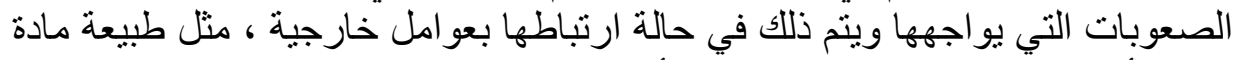

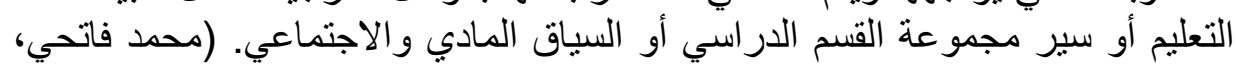

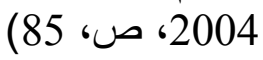

إذن الهدف من التقويم التكويني هو ضبط سيرورة التعلم و تقديم معلومات

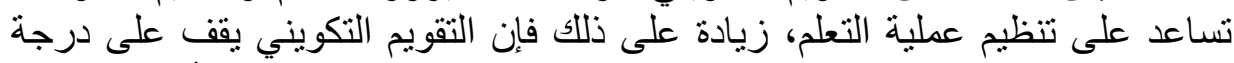

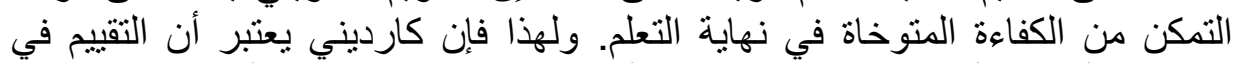

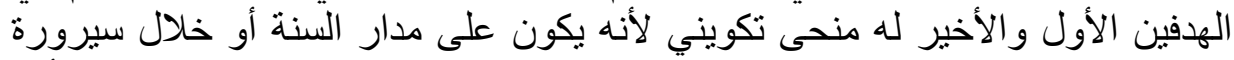

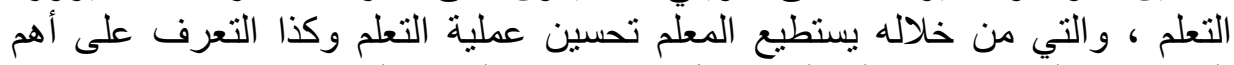
الصعوبات التي تعثرض المتعلم وتحول دون تحقيق الكفاءة اللازمة.

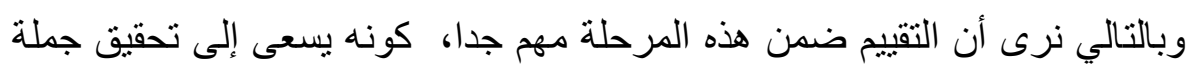

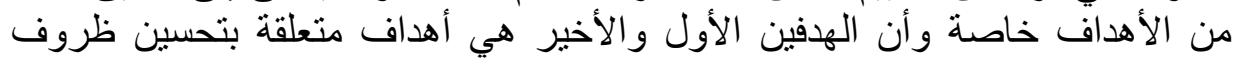

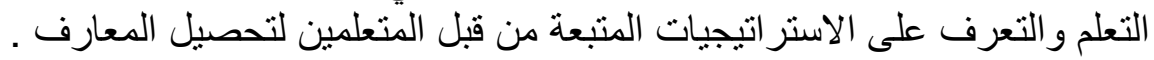

ب- يعتبر التقييم في الهدفين الثاني والثالث حسب تصنيف كاديف كارديني تقييما إجماليا

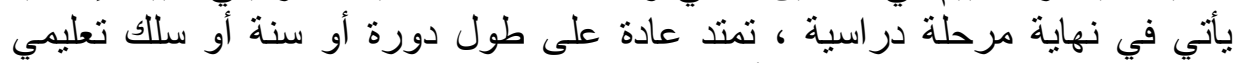

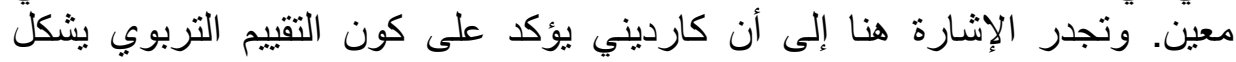

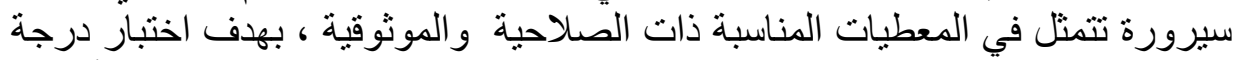

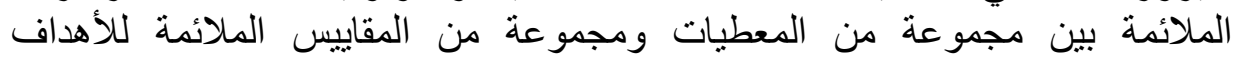

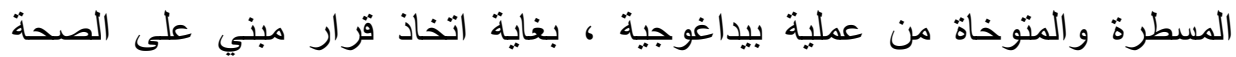

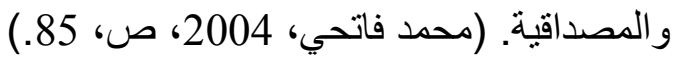

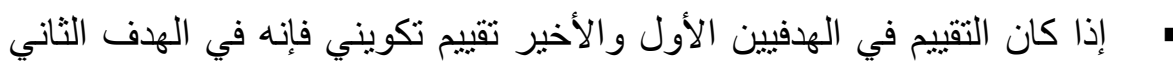

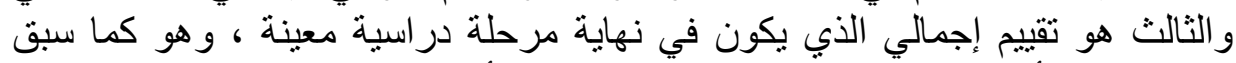

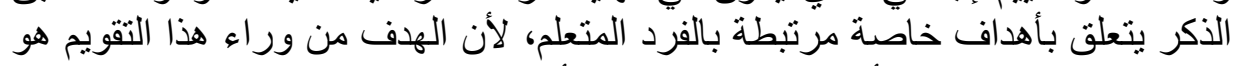

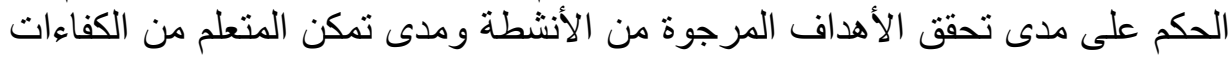

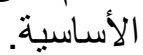

و أخيرا نتوصل إلى أن التقييم حسب كارديني مقسم إلى قسمين الأول تكويني

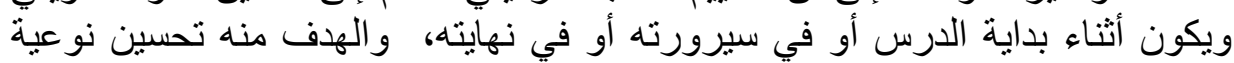

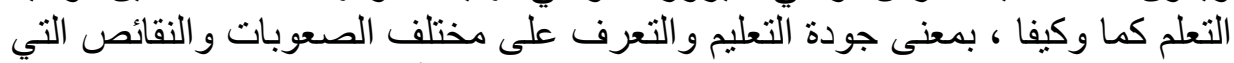

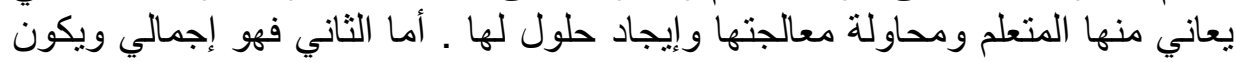

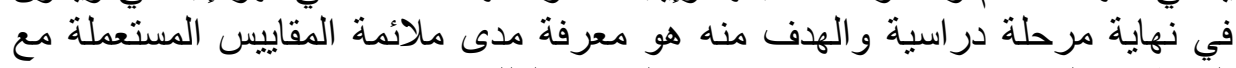

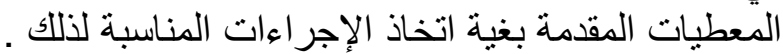




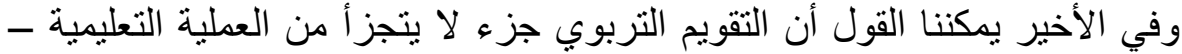

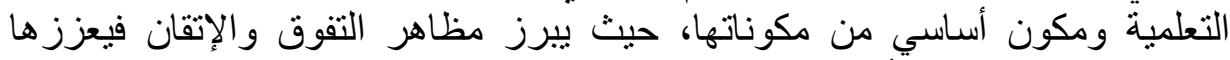
ويكثف باستمر ار عن أنواع القصور في الانجاز ويصحدها، كما يؤسس لبناء خطة تحقق تقدما مستمر ا ومطردا.

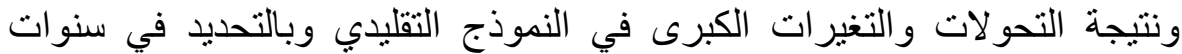

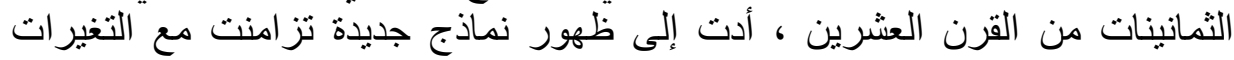

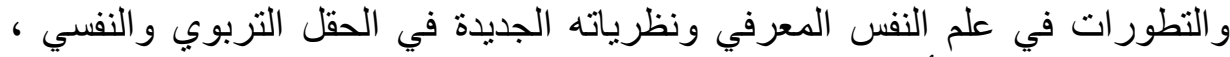

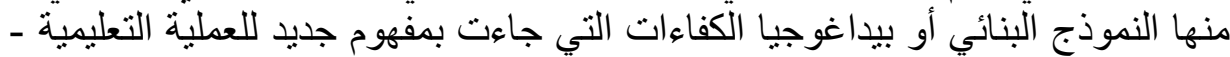

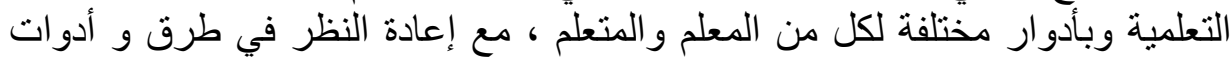
القياس و التقويم التربوي ـ هذا الأخير الذي يؤدي إلى تطوير التير عملية التعليم و التعلم ، و لا لا سيما تحصيل المتعلم الكفاءات تدريجيا بتوجيه التعلم نحو التعلم الذاتي و التقويم الذاتئي.

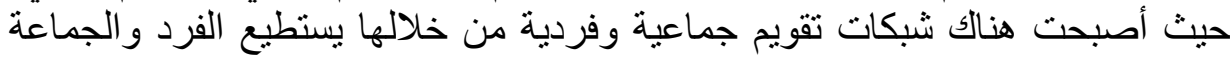

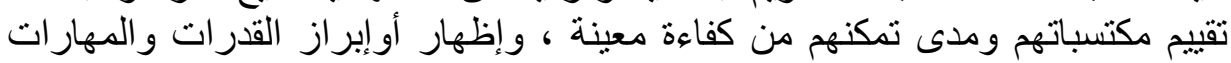

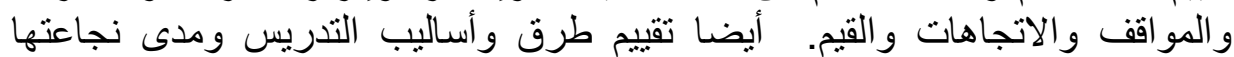

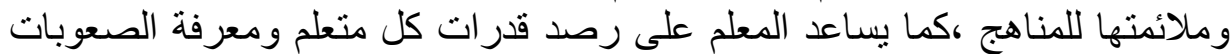

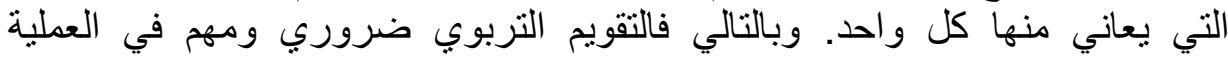

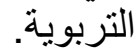

\section{قائمة المراجع المعتمد عليها:}

- الحسن اللحية، الكفايات في علوم التربية، إفريقيا الثرق، ط1 ،المغرب ،

$$
\begin{aligned}
& \text { - العربي اسليماني، الكفايات في التعليم - من أجل مقاربة شمولية - مطبعة } \\
& \text { النجاح الجديدة، ط 1، المغرب، } 2006 .
\end{aligned}
$$

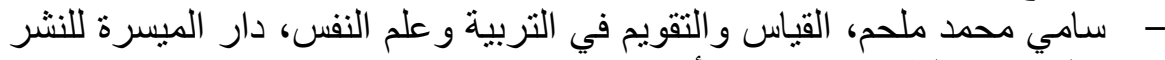

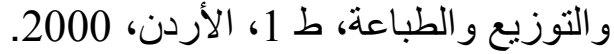

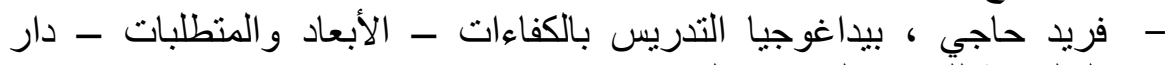$$
\text { الخلدونية للنشر والتوزيع، الجزائر ، }
$$

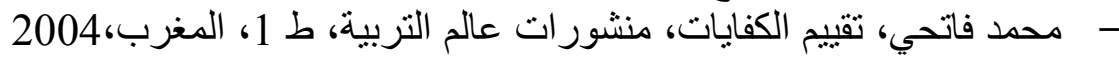

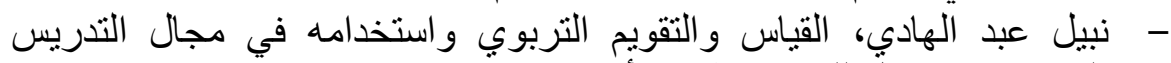
الصفي، دار و ائل للنشر ، ط2، الأردن، دس. 